\title{
A multi-scale analysis of bull sperm methylome revealed both species peculiarities and conserved tissue-specific features
}

Jean-Philippe Perrier ${ }^{1,2}$, Eli Sellem,3, Audrey Prézelin ${ }^{1}$, Maxime Gasselin ${ }^{1}$, Luc Jouneau ${ }^{1}$, François Piumi ${ }^{1,4,5}$, Hala Al Adhami ${ }^{1,6}$, Michaël Weber ${ }^{6}$, Sébastien Fritz ${ }^{3,7}$, Didier Boichard', Chrystelle Le Danvic ${ }^{3,8}$, Laurent Schibler ${ }^{3}$, Hélène Jammes ${ }^{1}$ and Hélène Kiefer ${ }^{1 *}$ (1)

\begin{abstract}
Background: Spermatozoa have a remarkable epigenome in line with their degree of specialization, their unique nature and different requirements for successful fertilization. Accordingly, perturbations in the establishment of DNA methylation patterns during male germ cell differentiation have been associated with infertility in several species. While bull semen is widely used in artificial insemination, the literature describing DNA methylation in bull spermatozoa is still scarce. The purpose of this study was therefore to characterize the bull sperm methylome relative to both bovine somatic cells and the sperm of other mammals through a multiscale analysis.

Results: The quantification of DNA methylation at CCGG sites using luminometric methylation assay (LUMA) highlighted the undermethylation of bull sperm compared to the sperm of rams, stallions, mice, goats and men. Total blood cells displayed a similarly high level of methylation in bulls and rams, suggesting that undermethylation of the bovine genome was specific to sperm. Annotation of CCGG sites in different species revealed no striking bias in the distribution of genome features targeted by LUMA that could explain undermethylation of bull sperm. To map DNA methylation at a genome-wide scale, bull sperm was compared with bovine liver, fibroblasts and monocytes using reduced representation bisulfite sequencing (RRBS) and immunoprecipitation of methylated DNA followed by microarray hybridization (MeDIP-chip). These two methods exhibited differences in terms of genome coverage, and consistently, two independent sets of sequences differentially methylated in sperm and somatic cells were identified for RRBS and MeDIP-chip. Remarkably, in the two sets most of the differentially methylated sequences were hypomethylated in sperm. In agreement with previous studies in other species, the sequences that were specifically hypomethylated in bull sperm targeted processes relevant to the germline differentiation program (piRNA metabolism, meiosis, spermatogenesis) and sperm functions (cell adhesion, fertilization), as well as satellites and rDNA repeats.

Conclusions: These results highlight the undermethylation of bull spermatozoa when compared with both bovine somatic cells and the sperm of other mammals, and raise questions regarding the dynamics of DNA methylation in bovine male germline. Whether sperm undermethylation has potential interactions with structural variation in the cattle genome may deserve further attention.
\end{abstract}

Keywords: DNA methylation, Sperm, Cattle, Satellite repeats

* Correspondence: helene.kiefer@inra.fr

'UMR BDR, INRA, ENVA, Université Paris Saclay, 78350 Jouy en Josas, France

Full list of author information is available at the end of the article

(c) The Author(s). 2018 Open Access This article is distributed under the terms of the Creative Commons Attribution 4.0 International License (http://creativecommons.org/licenses/by/4.0/), which permits unrestricted use, distribution, and reproduction in any medium, provided you give appropriate credit to the original author(s) and the source, provide a link to the Creative Commons license, and indicate if changes were made. The Creative Commons Public Domain Dedication waiver (http://creativecommons.org/publicdomain/zero/1.0/) applies to the data made available in this article, unless otherwise stated. 


\section{Background}

Sperm unique morphology and functions result from a long differentiation process that requires dynamic epigenetic reprogramming of the genome [1], which starts with the global erasure and reestablishment of DNA methylation marks in fetal and post-natal germ cells [2] and continues throughout adulthood. The maintenance of DNA methylation, the accumulation of non-coding RNAs, the implementation of post-translational histone modifications or sperm-specific variants and finally histone-toprotamine replacement then occur progressively during the sequential mitosis, meiosis, differentiation and maturation steps of spermatogenesis [3, 4]. The reorganization of epigenetic marks during spermatogenesis enables a dramatic compaction of the sperm nucleus, thus improving motility and DNA damage protection in the female genital tract, and plays a fundamental role in subsequent development of the embryo [5]. Alterations to the epigenetic reprogramming of the male germline may potentially affect sperm functions and fertilization efficiency [6], and numerous studies have reported associations between an abnormal sperm epigenome and a low sperm count or sperm dysmorphia, fertilization failures, poor embryogenesis, low pregnancy outcomes and metabolic disorders affecting the offspring [7-17]. Accordingly, studies in human cohorts $[12,18,19]$ and genetic or pharmacological alterations to DNA methylation in mice [20-22] have emphasized the prominent role of DNA methylation in male germ cell differentiation and male fertility.

Comparatively, studies on DNA methylation in bovine spermatozoa are still scarce, and have often focused on candidate loci [23-25]. Recent genome-wide studies have identified sperm DNA methylation marks associated with subfertility in buffalo and bulls $[26,27]$, as well as regions that are hypermethylated in sperm relative to the embryo, studied using a platform dedicated to small samples [28]. However, a comprehensive view of the sperm methylome in bovine species is still lacking, even though this knowledge could enable promising advances in the cattle industry. Indeed, domestication, the creation of highly specialized breeds and decades of genetic improvement have shaped the bovine genome [29]. This undoubtedly has also had a profound impact on the methylome, since DNA methylation is directly affected by the CpG content of the genome and its alteration by DNA polymorphism [30]. Whether these changes are of functional significance and contribute to the establishment of phenotypes needs to be ascertained. In addition, in a context of genomic selection, more information on the epigenetic features transferred to the embryo alongside the paternal genetic heritage is necessary in order to improve semen quality control procedures as well as to guarantee semen fertility and proper embryo development.
In order to contribute knowledge in this field, we established a thorough description of the methylome of bull spermatozoa at different scales, using luminometric methylation assay (LUMA), methylated DNA immunoprecipitation (MeDIP), reduced representation bisulfite sequencing (RRBS) and pyrosequencing. We report here on the global DNA methylation level of bull sperm relative to both bovine somatic cells and the sperm of other mammals, and on a comparison of genome-wide methylation patterns between bovine sperm and somatic cells.

\section{Methods}

\section{Animals and cell/tissue collection}

All study methods were implemented in accordance with EU guidelines and regulations (Directive 2010/63/UE). For animals maintained in INRA facilities, the experimental protocols were approved by the INRA local Ethics Committee (COMETHEA, authorization numbers 12/160 and Méjusseaumes Animal Care committee 0162503). The bull samples originated from bulls selected for artificial insemination and were provided by commercial companies: Montbéliarde breed by GEN'IATEST (France) and UMOTEST (France), Holstein and Normande breeds by EVOLUTION (France) and Belgian White Blue breed by AWE (Belgium). Other bovine tissues were collected from Holstein cows maintained at the INRA experimental farm (UCEA, INRA, France). The ram, goat and boar semen and blood samples were supplied by commercial companies (OSON, Capgenes and LNCR, respectively, France). Mice semen samples were collected from the caudal epididymis of 7-week-old male C57Bl/6JOlaHsd mice supplied by Harlan Laboratory (Netherlands) and euthanized by cervical dislocation. Stallion semen was supplied by Dr. M. Magistrini (UMR INRA 0085 PRC, France). Human sperm samples originated from patients included in a PHRC METASPERME study, coordinated by Dr. R. Levy (Laboratoire d'Histologie Embryologie Cytogénétique CECOS, Hôpital Jean Verdier, France); this study received the approval from French ethics board (Conseil d'évaluation éthique pour les recherches en santé, CERES) and all the patients gave their informed written consent to participate.

In Fig. 1c-d, semen and blood from the same individuals were collected using standard procedures on bulls and rams maintained in semen production centers. Total blood was used for DNA extraction. For both bulls and rams, collected semen was extended with Optidyl (CryoVet) and either underwent direct DNA extraction (fresh semen) or was subjected to standard techniques for semen processing (straw conditioning, freezing and storage in liquid nitrogen; frozen semen). Other bull semen samples were in the form of frozen straws stored in liquid nitrogen. 


\section{a}

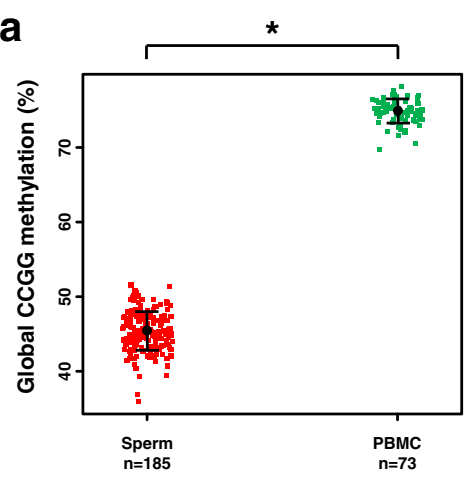

$$
\text { c }
$$

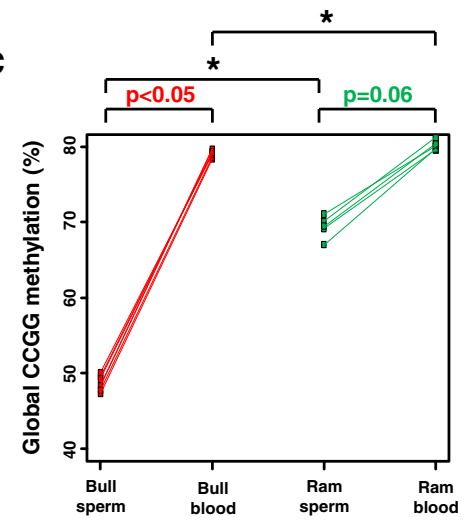

b

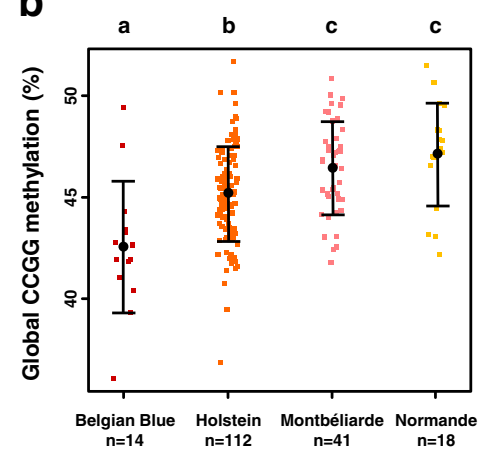

d
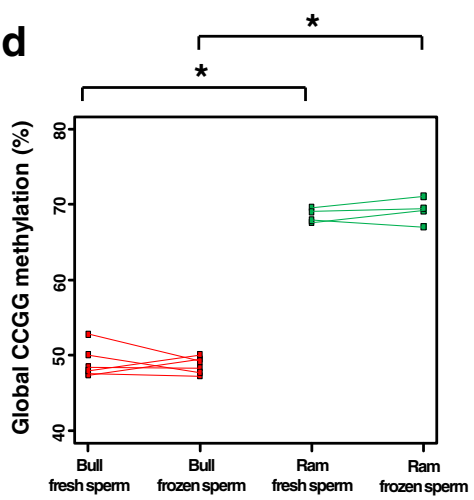

e

\begin{tabular}{|c|c|c|c|c|c|c|c|}
\hline & \\
\hline & Cattle & Sheep & Horse & Pig & Mouse & Human & Goat \\
\hline $\begin{array}{l}\text { Global CCGG methylation in } \\
\text { sperm (mean } \% \pm \text { SD) }\end{array}$ & $\begin{array}{c}45.5 \pm 2.6 \text { (min.) } \\
n=185\end{array}$ & $\begin{array}{l}69.4 \\
n=5\end{array}$ & $\begin{array}{c}76.1 \text { (max.) } \\
\mathrm{n}=2\end{array}$ & $\begin{array}{l}72.6 \\
\mathrm{n}=3\end{array}$ & $\begin{array}{l}59.2 \\
n=2\end{array}$ & $\begin{array}{l}57.1 \\
n=7\end{array}$ & $\begin{array}{l}67.2 \\
n=2\end{array}$ \\
\hline Number of CCGG sites & $1,987,520$ & $1,855,703$ & $2,602,517$ (max.) & $2,366,897$ & $1,548,665$ (min.) & $2,196,730$ & $N A$ \\
\hline \multicolumn{8}{|l|}{ Gene features (\%) } \\
\hline Promoter-TSS & 4.9 & 3.9 & 3.0 (min.) & 3.4 & 6.1 & 7.2 (max.) & $N A$ \\
\hline Intron & 27.0 & 30.4 & 20.8 (min.) & 25.2 & 30.4 & 39.1 (max.) & $N A$ \\
\hline Exon & 5.2 & 5.4 & 3.0 (min.) & 4.1 & 7.1 & 7.3 (max.) & $N A$ \\
\hline TTS & 2.0 & 2.4 & 1.5 (min.) & 1.9 & 2.1 & 2.7 (max.) & $N A$ \\
\hline 3'UTR & 0.4 (min.) & 0.4 (min.) & 1.1 & 0.8 & 1.1 & 1.8 (max.) & $N A$ \\
\hline 5'UTR & 2.7 & 1.8 (min.) & 1.9 & 3.2 & 7.1 & 8.6 (max.) & $N A$ \\
\hline Intergenic & 57.8 & 55.7 & 68.7 (max.) & 61.4 & 46.1 & 33.3 (min.) & $N A$ \\
\hline \multicolumn{8}{|l|}{ CpG density (\%) } \\
\hline Island & 14.8 (max.) & 11.3 & NA & 12.8 & 8.2 (min.) & 12.1 & $N A$ \\
\hline Shore & 12.8 & 13.0 & $N A$ & 13.2 (max.) & 5.3 (min.) & 9.1 & NA \\
\hline Shelve & 6.0 & 6.2 (max.) & $N A$ & 6.2 (max.) & 2.8 (min.) & 5.0 & $N A$ \\
\hline Open sea & 66.4 (min.) & 69.5 & $N A$ & 67.8 & 83.7 (max.) & 73.8 & $N A$ \\
\hline \multicolumn{8}{|l|}{ Repeats (\%) } \\
\hline LINE & 16.9 & 15.3 & 6.3 & 5.9 (min.) & 20.3 (max.) & 7.0 & $N A$ \\
\hline SINE & 11.5 & 12.7 & 13.6 & 26.7 & 10.3 (min.) & 33.6 (max.) & $N A$ \\
\hline LTR & 4.4 & 2.9 (min.) & 3.8 & 3.1 & 12.6 (max.) & 7.0 & $N A$ \\
\hline Satellite & 1.6 (max.) & 0.1 (min.) & 0.3 & 0.2 & 0.1 (min.) & 0.6 & $N A$ \\
\hline Other & 2.5 & 2.3 & 2.7 & 2.7 & 1.8 (min.) & 4.8 (max.) & $N A$ \\
\hline No overlapping repeat & 63.1 & 66.7 & 73.3 (max.) & 61.4 & 54.9 & 47.0 (min.) & $N A$ \\
\hline
\end{tabular}

Fig. 1 (See legend on next page.) 
(See figure on previous page.)

Fig. 1 Global DNA methylation level measured by LUMA is low in bovine sperm. a Global DNA methylation level in bovine sperm and PBMCs. Each colored dot represents one individual. The black dots and horizontal bars indicate the means \pm standard deviations. The difference between cell types is highly significant ( $p<2.2 \mathrm{e}-16$, Welch's t-test). $\mathbf{b}$ Global DNA methylation level of sperm in four bovine breeds. The effect of the breed on CCGG methylation is significant ( $p<0.05$, one-way analysis of variance for independent samples). Significant differences between breeds are indicated by different letters ( $p<0.05$, multiple comparisons of means using Tukey's test). $\mathbf{c}$, $\mathbf{d}$ Global DNA methylation level in bull and ram samples. Significant differences between independent samples are indicated by asterisks $(p<0.05$, permutation test), while paired samples are connected by plain lines. c Global DNA methylation level in blood cells and semen for bulls $(n=6)$ and rams $(n=5)$. The $p$-values are indicated in red (bulls) and green (rams) for comparisons involving samples collected from the same individuals (permutation test for paired samples). $\mathbf{d}$ Global DNA methylation level in bull $(n=6)$ and ram $(n=4)$ sperm cells from fresh and frozen semen. The difference between fresh and frozen semen is not significant. e Global sperm DNA methylation level and CCGG distribution in several mammalian species. The CCGG sites were annotated relative to gene features, CpG density and overlapping repeats. For each genomic feature examined, species with extreme values are indicated (min. and max.). In the bovine genome, CCGG sites are particularly enriched in CpG islands and satellites, and are within the ranges of other species for other genomic features. SD: standard deviation

For all semen samples except those from humans and stallions, the possible contamination of spermatozoa by somatic cells was checked systematically under the microscope and confirmed to be below detectable levels. The human and stallion semen samples contained observable somatic cells and were therefore processed as previously described to ensure the absence of potential contamination: the human semen samples were subjected to a stringent somatic cell lysis protocol [18] and the sperm from stallions were purified by single layer centrifugation using Androcoll-E-Large (SLU, Uppsala, Sweden) [31].

Primary cultures of fibroblasts were derived from ear skin biopsies from three separate adult heifers and cultured until passage 11 in Dulbecco's modified Eagle medium supplemented with $10 \%$ fetal calf serum and $1 \%$ penicillin-streptavidin (Life Technologies) at $38{ }^{\circ} \mathrm{C}$ with $5 \% \mathrm{CO}_{2}$. Livers were obtained from adult cows slaughtered at the INRA experimental facilities. Peripheral blood mononuclear cells (PBMCs) were isolated from blood collected from the jugular vein and centrifuged using a Ficoll gradient. To obtain the monocyte fraction, PBMCs were incubated in the presence of microbeads conjugated to monoclonal anti-CD14 antibodies (mouse IgG2a; Miltenyi Biotec) in MACS BSA buffer, for 15 min. at $4{ }^{\circ} \mathrm{C}$ under gentle agitation. Magnetic separation was then performed using MS Columns following the manufacturer's instructions. The tissues and cells were snap-frozen in liquid nitrogen and stored at $-80{ }^{\circ} \mathrm{C}$ until DNA extraction.

The sample types and experiments performed are summarized in Table 1.

\section{Genomic DNA extraction and genotyping}

One straw of bull semen was used for DNA extraction (about 20 million spermatozoa). After thawing at $37{ }^{\circ} \mathrm{C}$, the semen was washed with phosphate buffer saline (PBS) to remove the extender, and incubated overnight at $55^{\circ} \mathrm{C}$ in $200 \mu \mathrm{l}$ lysis buffer $(10 \mathrm{mM}$ Tris- $\mathrm{HCl} \mathrm{pH} \mathrm{7.5,}$ $25 \mathrm{mM}$ EDTA, 1\% SDS, $75 \mathrm{mM} \mathrm{NaCl}, 50 \mathrm{mM}$ dithiothreitol (DTT) and $0.5 \mu \mathrm{g}$ glycogen) in the presence of $0.2 \mathrm{mg} / \mathrm{ml}$ proteinase $\mathrm{K}$. After incubation with $25 \mu \mathrm{g} / \mathrm{ml}$ RNAse A for $1 \mathrm{~h}$ at $37^{\circ} \mathrm{C}$, genomic DNA was extracted twice using phenol and phenol:chloroform (1:1), then ethanol precipitated and washed. The dried pellet

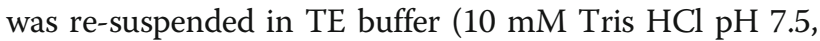
$2 \mathrm{mM}$ EDTA) and the DNA concentration was measured using a Qubit 2.0 Fluorometer (Invitrogen). Fresh bull semen, total blood from bulls and rams, fresh or frozen semen from rams, boars, mice, goats, processed semen from stallions and men were treated in an identical manner as the frozen straws from bull semen.

DNA extraction from liver samples was performed as described elsewhere [32]. The same procedure was used for fibroblasts and monocytes, except that the cells were lysed by the direct addition of lysis buffer and proteinase $\mathrm{K}$ to the cell pellet.

The genotyping of two Montbéliarde bulls was performed by LABOGENA (France) on semen and blood DNA from the same individuals using the commercially available BovineSNP50 v2 BeadChip (Illumina). Genotypes were determined using the Genotyping Module of GenomeStudio software (Illumina). For each animal, copy number variations (CNVs) were searched for and compared between tissues. The Log R Ratio (LRR, normalized measurement of total signal intensity) and $\mathrm{B} \mathrm{Al}$ lele Frequency (BAF, measurement of the allelic intensity ratio) were used to infer copy number changes in the genome. For example, in the presence of a deletion, LRR values increase and BAF values cluster around 0 or 1 but are absent at around 0.5, due to a lack of heterozygotes. LRR and BAF were then plotted along the genome and compared between tissues.

\section{In silico analyses}

A script developed in house was used to extract the coordinates of all the CCGG sites present in the genomes of different species (cattle, sheep, horse, pig, mouse and human; Fig. 1e). The CCGG sites were then annotated relative to different gene features, $\mathrm{CpG}$ density and 
Table 1 Samples and experiments

\begin{tabular}{|c|c|c|c|c|c|}
\hline Experiment & Species & Breed/strain & Sample type & Sample number & Figures \\
\hline \multirow[t]{16}{*}{ LUMA } & Cattle & Holstein & PBMCS & 73 & Fig. 1a \\
\hline & Cattle & Belgian White Blue & Sperm, frozen & 14 & Fig. 1a-b, e \\
\hline & Cattle & Holstein & Sperm, frozen & 112 & Fig. 1a-b, e \\
\hline & Cattle & Montbéliarde & Sperm, frozen & 41 & Fig. 1a-b, e \\
\hline & Cattle & Normande & Sperm, frozen & 18 & Fig. 1a-b, e \\
\hline & Cattle & Montbéliarde & Sperm, frozen & 6 & Fig. 1c-d \\
\hline & Cattle & Montbéliarde & Total blood & 6 & Fig. 1c \\
\hline & Sheep & Ile-de-France & Sperm, frozen & 5 & Fig. 1c-d, e \\
\hline & Sheep & Ile-de-France & Total blood & 5 & Fig. 1c \\
\hline & Cattle & Montbéliarde & Sperm, fresh & 6 & Fig. 1d \\
\hline & Sheep & Ile-de-France & Sperm, fresh & 4 & Fig. 1d \\
\hline & Horse & Welsh & Sperm, fresh & 2 & Fig. 1e \\
\hline & Pig & mixed & Sperm, fresh & 3 & Fig. 1e \\
\hline & Mouse & C57BI/6JOlaHsd & Sperm, fresh & 2 & Fig. 1e \\
\hline & Human & & Sperm, frozen & 7 & Fig. 1e \\
\hline & Goat & Alpine & Sperm, frozen & 2 & Fig. 1e \\
\hline \multirow[t]{2}{*}{ Genotyping } & Cattle & Montbéliarde & Sperm, fresh & 2 & Additional file 1: Figure S2 \\
\hline & Cattle & Montbéliarde & Total blood & 2 & Additional file 1: Figure S2 \\
\hline \multirow[t]{3}{*}{ MeDIP } & Cattle & Holstein & Sperm, frozen & 4 & Figs. 2, 3, 4, 6 \\
\hline & Cattle & Holstein & Liver & 4 & Figs. 2, 3, 4, 6 \\
\hline & Cattle & Holstein & Fibroblasts & 3 & Figs. 2, 3, 4, 6 \\
\hline \multirow[t]{3}{*}{ RRBS } & Cattle & Holstein & Sperm, frozen & 2 & Figs. 2, 3, 5, 6 \\
\hline & Cattle & Holstein & Monocytes & 2 & Figs. 2, 3, 5, 6 \\
\hline & Cattle & Holstein & Fibroblasts & 2 & Figs. 2, 3, 5, 6 \\
\hline
\end{tabular}

All the samples were independent, except for (i) the sperm and blood samples in Fig. 1c-d that were collected on the same bulls and rams, and (ii) two fibroblast samples and two livers that were collected on the same animals. Two independent amplifications of the same fibroblast cultures were used for MeDIP and RRBS. The sperm and blood DNA samples used for genotyping were the same as used for LUMA, Fig. 1c-d. PBMCs: peripheral blood mononuclear cells

repeats by means of a pipeline developed in house (https://github.com/FAANG/faang-methylation/tree/ master/RRBS-toolkit/Annotation) and using the genome annotation features indicated in Additional file 1: Table S1. The following criteria were applied: promoter-TSS, -1000 to +100 bp relative to the transcription start site (TSS); TTS: -100 to +1000 bp relative to the transcription termination site (TTS); shore, up to $2000 \mathrm{bp}$ from a CpG island (CGI); and shelve up to 2000 bp from a shore. A site/fragment was considered to belong to a CGI (respective shore and shelve) if an overlap of at least $75 \%$ was observed between the site/fragment and the CGI (respective shore and shelve). A site/fragment was considered as being overlapped by a repetitive element whatever the extent of this overlapping.

In Additional file 1: Tables S2 and S3, in silico reduced representation (RR) genomes digested by MspI restriction enzyme were produced for different species and using different size selection criteria by means of another pipeline developed in house (https:/github.com/
FAANG/faang-methylation/tree/master/RRBS-toolkit/ $R R$ genome). The RR genome fragments were then annotated as explained above.

\section{Luminometric methylation assay (LUMA)}

Global DNA methylation levels were quantified using LUMA, as previously described [33, 34]. Briefly, $1 \mu \mathrm{g}$ of genomic DNA was cleaved using the isochizomeres HpaII (methylation sensitive) and MspI (non-methylation-sensitive) in two separate reactions and in the presence of EcoRI to standardize for DNA amounts. The three enzymes were purchased from New England Biolabs. The protruding ends were then used as templates for pyrosequencing with the Pyromark Q24 device and Pyromark Gold Q96 reagents (Qiagen). The luminometric signals produced by either the sequential incorporation of $\mathrm{C}$ and $\mathrm{G}$ nucleotides (reflecting the number of CCGG sites digested by HpaII or MspI) or the sequential incorporation of $\mathrm{A}$ and $\mathrm{T}$ nucleotides (reflecting the number of AATT sites digested by EcoRI), were then 
quantified using Pyromark Q24 software. Each sample was assayed in duplicate. The global methylation percentage per sample was then calculated as follows:

Methylation $\%=100-\frac{\text { Average signal obtained with HpaII after EcoRI normalization }}{\text { Average signal obtained with MspI after EcoRI normalization }} * 100$

The conditions were compared using non-parametric tests suited to small samples (permutation tests for two independent samples or for two paired samples according to the situation, with Monte-Carlo sampling of 100,000 permutations) or using t-test and analysis of variance when appropriated (larger samples with a normal distribution).

\section{Methylated DNA immunoprecipitation (MeDIP), microarray hybridization and data analysis}

MeDIP and quality controls by PCR were performed as described elsewhere [32]. The antibody used for immunoprecipitation was BI-MECY-1000 5-methylcytidine antibody (Eurogentec). To prevent any technical bias, the products of five independent MeDIP experiments were pooled for each sample. After moderate genome amplification, the pooled MeDIP reactions and corresponding input DNA were labelled with $\mathrm{Cy} 3$ and $\mathrm{Cy} 5$ and hybridized on a Roche-NimbleGen 3x720K microarray, with technical dye-swaps for every sample. The microarray targeted the promoter region $(-2000$ to + $1360 \mathrm{bp}$ relative to the gene start) of 21,296 bovine genes, according to an annotation file downloaded from the Johns Hopkins University Center for Computational Biology FTP website (ftp://ftp.ccb.jhu.edu/pub/data/assembly/Bos_taurus/Bos_taurus_UMD_3.0/annotation/; accessed Aug. 2010). The microarray design and hybridization protocol, as well as more details on the data analysis, can be found in [35]. The identification of regions of interest containing clusters of probes enriched in at least one tissue, the identification of differentially methylated regions (DMRs) among these regions of interest, as well as the calculation of mean percentages of enriched probes (Pr) in each tissue for each region $r$ (DMR or region of interest), are detailed in the Additional file 1: Supplementary methods. Three Pr were obtained per region: $\operatorname{Pr}_{\text {sperm }}, \operatorname{Pr}_{\text {liver }}$ and $\mathrm{Pr}_{\text {fibro- }}$ blasts. The scatterplot shown in Fig. 3d illustrates the $\mathrm{Pr}_{\text {liver }}-\mathrm{Pr}_{\mathrm{sperm}}$ and $\mathrm{Pr}_{\text {fibroblasts }}-\mathrm{Pr}_{\text {sperm }}$ differences for the regions of interest (in black) and for the DMRs specific to the comparison between sperm and somatic cells (in red). Positive values for both $\operatorname{Pr}_{\text {liver }}-\operatorname{Pr}_{\text {sperm }}$ and $\mathrm{Pr}_{\text {fibroblasts }}-\mathrm{Pr}_{\text {sperm }}$ indicated that the two somatic cell types were more methylated than sperm in the region considered, while negative values for both $\operatorname{Pr}_{\text {liver }}$ $\operatorname{Pr}_{\text {sperm }}$ and $\operatorname{Pr}_{\text {fibroblasts }}-\operatorname{Pr}_{\text {sperm }}$ indicated the contrary. Similarly, an opposite sign for the values of $\operatorname{Pr}_{\text {liver }}$ $\operatorname{Pr}_{\text {sperm }}$ and $\operatorname{Pr}_{\text {fibroblasts }}-\operatorname{Pr}_{\text {sperm }}$ reflected the contrasting behaviors of liver and fibroblasts. Among the DMRs, those undermethylated in sperm were selected based on a positive value for both $\operatorname{Pr}_{\text {liver }}-\operatorname{Pr}_{\text {sperm }}$ and $\operatorname{Pr}_{\text {fibroblasts }}-\operatorname{Pr}_{\text {sperm }}$ and were annotated as explained regarding the in silico analyses, together with the 27,684 regions of interest. Genes containing DMRs were subjected to DAVID analysis (Database for Annotation, Visualization and Integrated Discovery; [36]) using genes containing the 27,684 regions of interest as the background.

\section{Reduced representation bisulfite sequencing (RRBS) and data analysis}

RRBS libraries were prepared as described elsewhere [37, 38]. Briefly, $200 \mathrm{ng}$ of genomic DNA were digested by MspI (Thermo Scientific), end-repaired and ligated to 55 bp Illumina adapters for paired-end sequencing. Size selection by gel excision was performed in order to select fragments ranging from 150 to $400 \mathrm{bp}$ (genomic fragments of 40-290 bp + adapters). The DNA was then purified using the MinElute gel extraction kit (Qiagen) and then bisulfite-converted twice consecutively with the EpiTect bisulfite kit (Qiagen), following the manufacturer's instructions for DNA extracted from FFPE tissues. Converted DNA was amplified with Pfu Turbo Cx hotstart DNA polymerase (Agilent) using 14 PCR cycles for sperm and fibroblasts and 12 cycles for monocytes. The libraries were then purified using Agencourt Ampure beads (Beckman-Coulter) and sequenced on an Illumina HiSeq2500 sequencer to produce 75 bp paired-end reads (Integragen SA, France).

RRBS sequences were analyzed using an integrated pipeline combining scripts developed in house in Python, R and Shell, together with external tools (https:// github.com/FAANG/faang-methylation/tree/master/ RRBS-toolkit/). Details about the analysis and the identification of differentially methylated cytosines (DMCs) are provided in the Additional file 1: Supplementary methods.

For each tissue, the mean methylation percentage was calculated (mean of the methylation percentages obtained in the two biological replicates) as well as the difference between two tissues (Additional file 2, column L). The scatterplot shown in Fig. 3e illustrates the differences between monocytes and sperm and between fibroblasts and sperm for the 1,580,644 CpGs covered by 5 to 500 uniquely mapped reads (CpGs 5-500) in all six samples (in black) and for the DMCs specific to the comparison between sperm and somatic cells (in red). Among these DMCs, those undermethylated in sperm were selected based on a positive value for both differences. Together with the CpGs 5-500, they were then annotated relative to gene features, CGIs and repeats as explained for the in silico analyses. Genes containing 
DMCs were subjected to DAVID analysis using genes containing the 1,580,644 CpGs 5-500 as the background.

To better characterize repetitive elements, an artificial genome containing the consensus sequence of each bovine repeat was constituted from the Repbase database [39]. Reads were aligned on this artificial genome as explained above, and the average methylation percentage was calculated for each repeat and each sample (average methylation percentage for all CpGs included in one genomic repeat and covered by either 5-500 reads or by $>500$ reads).

\section{Bisulfite-pyrosequencing}

Bisulfite conversion was performed on $1 \mu \mathrm{g}$ genomic DNA as described elsewhere [40]. After ethanol precipitation, the DNA pellet was re-suspended in $20 \mu \mathrm{l} \mathrm{H}_{2} \mathrm{O}$.

For LSM4 and BTSAT4, primers were designed using the MethPrimer program [41] and amplifications were carried out from $1 \mu \mathrm{l}$ treated DNA with Platinum Taq DNA polymerase (Invitrogen), according to the manufacturer's instructions with variable $\mathrm{MgCl}_{2}$ concentrations. The following program was used: $3 \mathrm{~min}$. at $94{ }^{\circ} \mathrm{C}$ followed by 50 cycles of $30 \mathrm{~s}$. at $94{ }^{\circ} \mathrm{C}, 1 \mathrm{~min}$. at variable hybridization temperatures, $1 \mathrm{~min}$. at $72{ }^{\circ} \mathrm{C}$, and finally $10 \mathrm{~min}$. at $72{ }^{\circ} \mathrm{C}$. For $D D X 4$ and $S Y C P 3$, primers were designed using the Pyromark assay design software (Qiagen) and amplifications were performed using the Pyromark PCR kit (Qiagen) according to the manufacturer's instructions. The primers used to amplify each region are listed in Additional file 1: Table S4, together with the hybridization temperatures and $\mathrm{MgCl}_{2}$ concentrations. The reverse primers were 5 '-biotinylated.

After denaturation and purification, the biotinylated antisense strand of PCR product was used as a template for pyrosequencing with $0.3 \mu \mathrm{M}$ pyrosequencing primer, using the Pyromark Q24 device and Pyromark Gold Q96 reagents (Qiagen). The pyrosequencing primers are listed in Additional file 1: Table S5. Each CpG was assayed in duplicate, and inconsistent duplicates (more than $5 \%$ difference) were repeated. The methylation percentage per $\mathrm{CpG}$ was then obtained by calculating the mean of all replicates that passed quality control by the Pyromark Q24 software. The statistical analysis was performed on the mean percentage per CpG using permutation tests as explained for LUMA.

\section{Results}

\section{Global DNA methylation level is low in bull sperm}

We first assessed the global level of DNA methylation in bull sperm relative to somatic cells (PBMCs) using LUMA [33, 34] on a large sample size. The average methylation at CCGG sites was dramatically lower in sperm (45.5\%, $n=185)$ than in PBMCs $(74.8 \%, n=73$; Fig. 1a). The standard deviations in this large sample were weak (2.6\% for sperm and $1.6 \%$ for PBMCs), demonstrating the limited inter-individual variability within each cell type and the reliability of the technique to assess global DNA methylation. Because the sperm samples were collected from Holstein, Montbéliarde, Normande and Belgian White Blue bulls, we investigated the effect of the breed on global sperm DNA methylation. Methylation was significantly lower in Belgian White Blue than in any other breed and significantly lower in Holstein than in Normande and Montbéliarde (Fig. 1b). A bootstrap analysis confirmed that these breed-related differences were not due to an unbalanced number of bulls from each breed (Additional file 1: Figure S1). These results demonstrated that global methylation varied across different bovine breeds, suggesting that the presence of DNA polymorphism could influence the global CCGG content and methylation. However, the range of variation (from $42.6 \%$ in Belgian White Blue to $47.1 \%$ in Normande) was weak relative to the $30 \%$ difference we observed between sperm and PBMCs, suggesting that sperm weaker methylation was not breed-dependent. To determine whether the global DNA methylation of sperm was comparably low in another species, we collected paired semen and blood samples from bulls and rams. While sperm was less methylated than blood in both species (Fig. 1c), the difference between the two cell types was much greater for bulls (30\% less methylation in sperm than in blood) than for rams (only $10 \%$ less methylation in sperm than in blood). Differences between species were observed in both cell types, but were broader for sperm (20\% difference) than for blood (only 1.2\% difference). In sperm, the difference between species was independent of the cryopreservation process (Fig. 1d).

This lower methylation of sperm may have resulted from a biased representation of the regions present in our sperm genomic DNA. Indeed, the high level of sperm chromatin compaction impeded the complete extraction of genomic DNA using standard procedures, which were therefore optimized by the addition of reducing agents such as DTT (see for instance [42]). The protocol we used during this study performed well for DNA extraction from human sperm (50 mM DTT, [7]). To investigate whether these conditions were also suited to bovine sperm, we used genomic DNA from two paired sperm and blood samples (the same samples as in Fig. 1c), both of which were purified in the presence of $50 \mathrm{mM}$ DTT, as a template for genotyping. As expected, the same genotype was obtained from blood and sperm DNA in each bull. Likewise, for each animal, CNV profiles were compared between tissues because any difference might be indicative of preferential extraction. The plots were similar and no gross discrepancies 
could be observed between tissues (Additional file 1: Figure S2). This result therefore ruled out the possibility that some specific regions of the bovine genome failed to be extracted from sperm chromatin under our experimental conditions.

Because the genomic distribution of CCGG sites may display species-specific variations that might influence the methylation results, we compared sperm CCGG methylation in several species relative to the genomic features available. In the horse, pig, mouse, human and goat, sperm DNA methylation level was much higher than that measured in bovine and closer to that determined in sheep (Fig. 1e). The CCGG distribution in the bovine genome was within the range observed in other species for most of the features examined, except for CGIs that accounted for $14.2 \%$ of total CCGG sites in bovine vs. 8.0 to $12.2 \%$ in other species. The important representation of bovine CCGGs in CGIs was balanced by a low representation in open sea (regions with a low CpG density). Most mammalian CGIs are unmethylated in somatic cells and can become methylated during development and disease [43]. Because blood cells (in which most CGIs are supposed to be unmethylated) displayed a roughly similar methylation level in bovine and sheep, it is unlikely that the lower level of DNA methylation in bull sperm resulted solely from the higher percentage of bovine CCGG sites in CGIs. Another remarkable feature of the bovine CCGG sites was their strong enrichment in satellites, which represented 1.6\% of all CCGGs vs. 0.1 to $0.6 \%$ in other species. However, whatever the species examined, the $<2 \%$ difference in CCGG sites present in satellites could not account for the $>10 \%$ difference in sperm methylation (Discussion).

Taken together, these data demonstrated that compared to somatic cells, bull sperm displayed a dramatically lower level of CCGG methylation which seemed to be specific to the bovine species. This lower methylation was neither related to the process of semen cryopreservation nor to a technical artefact, and could not be fully explained by the genomic distribution of CCGG sites in the bovine species.

\section{The tissue/cell type is a major determinant of DNA methylation landscapes in cattle}

Because high-throughput analyses were necessary to identify regions that were hypomethylated in bovine sperm, we decided to assess two cost-effective approaches which are widely used to study DNA methylation: MeDIP-chip [44] and RRBS [37]. MeDIP-chip enables precise targeting of specific regions in the genome through custom design of the microarray (in our case, $3360 \mathrm{bp}$ spanning the promoter and upstream region of each of the 21,296 bovine genes [35]), while RRBS offers a base-resolution analysis of CpG-rich regions through the combined use of enzymatic digestion (MspI) and the size selection of restriction fragments. Because no data were available regarding the optimal size window for RRBS in cattle, we conducted an in silico prediction of the genome coverage by RRBS and compared the results with those of MeDIP-chip (Additional file 1: Supplementary methods, Tables S2-S3). These in silico analyses suggested that the RRBS procedure could be successfully adapted to the bovine genome using MspI with a size window of 40-290 bp, and would lead to a base-resolution map of the methylome with coverage that would complement that of the MeDIP-chip.

Independent bovine samples were analyzed using MeDIP-chip (sperm, liver and fibroblasts) and RRBS (sperm, monocytes and fibroblasts) in order to determine cell type-dependent variations of the methylome using these two complementary technologies. For RRBS we selected CpGs covered by 5 to 500 uniquely mapped reads for each sample (CpGs 5-500), from which an average methylation rate was calculated. The average methylation in sperm (51.8\%) was higher than in fibroblasts (48\%) and lower than in monocytes (57.6\%; Additional file 1: Table S6). We next categorized the CpGs 5-500 into hypo- $(<20 \%$ methylation), intermediate $(20-80 \%$ methylation) and hypermethylated CpGs ( $>80 \%$ methylation) and observed a larger proportion of hypo- and a smaller proportion of intermediate CpGs in sperm than in somatic cells, which was counterbalanced by a large proportion of hypermethylated CpGs (Fig. 2a). This bimodal distribution of methylation in sperm probably explained the intermediate level of average methylation for CpGs 5500. It was noted that when only CpGs covered by more than 500 uniquely mapped reads were considered (CpGs $>500$ ), average methylation increased in monocytes (81. $4 \%)$ and in fibroblasts (66.6\%), but fell dramatically in sperm (22.5\%; Additional file 1: Table S6).

We next conducted descriptive analyses of the MeDIPchip and RRBS data. For MeDIP-chip, a normalized factor NEpi, representing the number of enriched probes at promoter $\mathrm{p}$ for sample $\mathrm{i}$, was calculated for all promoters and samples, and hierarchical clustering and principal component analysis (PCA) were run on the resulting matrix. For RRBS, PCA and hierarchical clustering were computed from the matrix of methylation percentages obtained for each CpG 5-500 and each sample (Fig. 2b). With both types of descriptive analysis, the samples were clearly clustered according to the tissue/cell type using both MeDIP-chip and RRBS. Interestingly, hierarchical clustering revealed that the distance between sperm and other cell types was more important than the distance between liver and fibroblasts or monocytes and fibroblasts, highlighting the methylation specificities of germinal cells compared to somatic cells. This could also be seen in PCA, where dimension 1 opposed sperm to one or both 
a

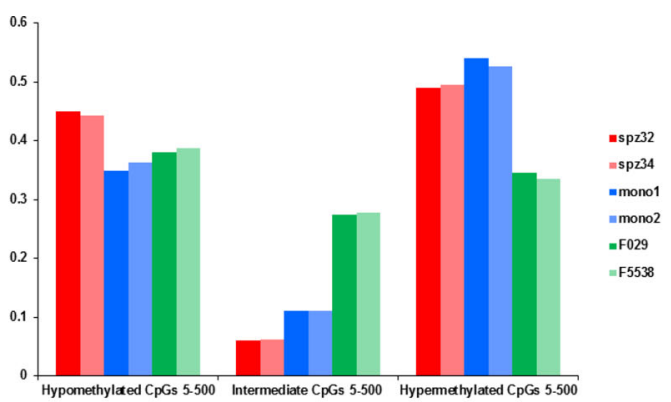

b

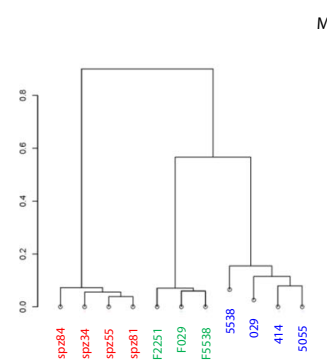

MeDIP

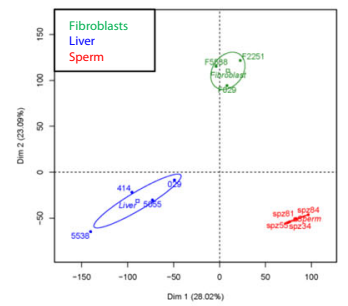

RRBS
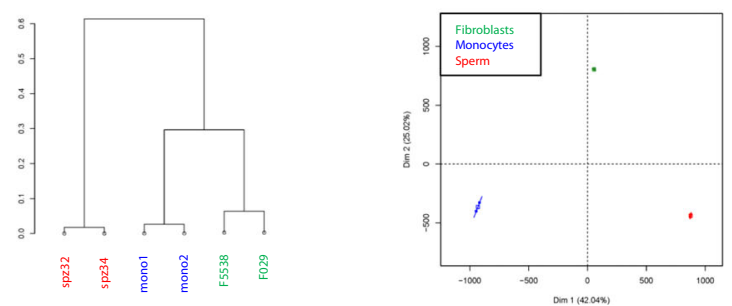

Fig. 2 Cell type is a major determinant of DNA methylation landscapes in cattle. a Proportion of hypo- ( $<20 \%$ methylation), intermediate (20-80\% methylation) and hypermethylated CpGs (> 80\% methylation) in each RRBS library, showing contrasted distributions between cell types. b Descriptive analyses. Upper panel: MeDIP-chip on sperm ( $n=$ 4 , red), fibroblasts ( $n=3$, green) and liver ( $n=4$, blue). For each sample $i$ and each promoter $p$, a normalized number of enriched probed NEpi was computed (see Additional file 1: Supplementary methods). Correlation clustering and PCA were then performed on the matrix of the normalized number of enriched probes. Lower panel: RRBS on sperm ( $n=2$, red), fibroblasts ( $n=2$, green) and monocytes $(n=2$, blue). Correlation clustering and PCA were run on the totality of CpGs covered between 5 and 500 reads in the six samples

somatic cells/tissue, while the difference between the two somatic cell types was more apparent along dimension 2 .

Our results therefore showed that the tissue/cell type represented the main source of variation in methylation, and that sperm-specific methylation profiles could emerge from our MeDIP and RRBS data.

\section{Identification of regions and CpGs hypomethylated in bull sperm}

We next ran a differential analysis on each pair of tissue/cell types. For MeDIP, we compared the proportion of enriched probes between two tissues/cell types in 27,684 regions of interest containing clusters of probes enriched in at least one tissue/cell type (see Additional file 1: Supplementary methods). This led to the identification of 4329 DMRs between sperm and liver; 3780 DMRs between sperm and fibroblasts and 2803 DMRs between fibroblasts and liver. The features of each DMR and the corresponding promoter regions are summarized in Additional file 3. For RRBS, we identified 298,901 DMCs between monocytes and sperm; 450,971 DMCs between fibroblasts and sperm, and 239,036 DMCs between monocytes and fibroblasts using stringent criteria (Additional file 1: Supplementary methods, Table S7 and Additional file 2).

Consistent with the results of clustering and PCA, the number of DMRs/DMCs was higher between sperm and any somatic cell type/tissue than between two somatic cell types, for both MeDIP and RRBS. Fig. 3a-b shows the distribution of DMRs and DMCs in different Venn territories corresponding to pairwise comparisons under MeDIP (Fig. 3a) and RRBS (Fig. 3b). DMRs and DMCs specific to the comparison between sperm and somatic cells could be deduced from these territories (in red). These 1678 DMRs and 174,103 DMCs were located at the intersection between the "sperm vs. somatic cell type 1 " and "sperm vs. somatic cell type 2" territories (yellow and orange) excluding the DMRs/DMCs also shared by the "somatic cell type 1 vs. somatic cell type 2" comparison (three-color territory). Because the comparison between sperm and fibroblasts was performed using both MeDIP and RRBS, the actual complementarity of the two technologies could be assessed using real data. As shown in Fig. 3c, only a limited subset of CpGs was shared by DMRs identified using MeDIP and DMCs identified using RRBS. This result, together with the in silico analysis indicating that the targeted regions were largely different under MeDIP-chip and RRBS, clearly demonstrated that we were able to identify two distinct subsets of sperm-specific DMRs/DMCs.

We next investigated whether these two subsets of sperm-specific DMRs/DMCs might display similar features in terms of variations in methylation. For both MeDIP (Fig. 3d) and RRBS (Fig. 3e), we plotted the differences in methylation between each somatic cell type and sperm for sperm-specific DMRs/DMCs. The appropriate background was used for each technology: the 27,684 regions of interest subjected to differential analysis in MeDIP and the 1,580,644 CpGs 5-500 covered in all six samples analyzed using RRBS. With both MeDIP and RRBS, background regions/CpGs (in black) were particularly concentrated around the center of the plot, illustrating that most of the regions/CpGs analyzed did not display cell type-dependent variations. By contrast, spermspecific DMRs/DMCs were located along a diagonal that 
a

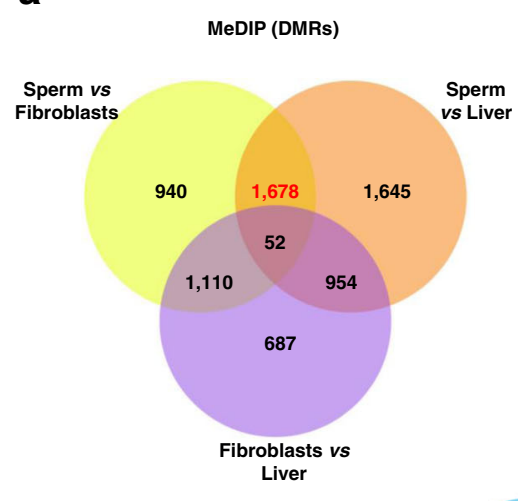

b

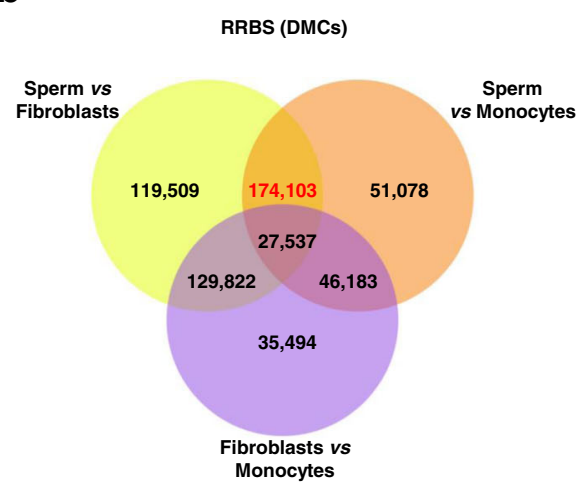

C

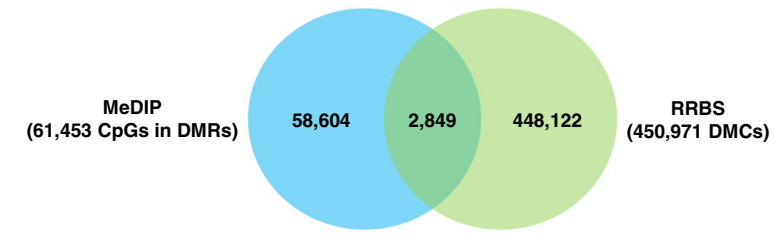

d

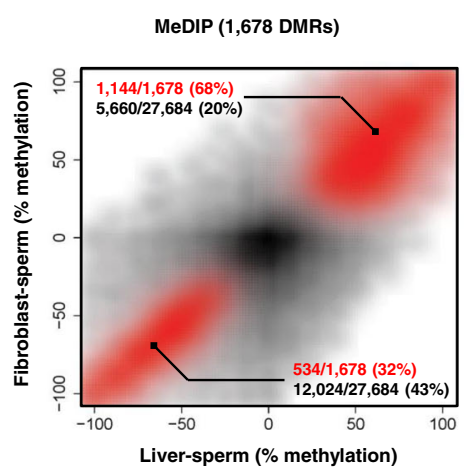

e

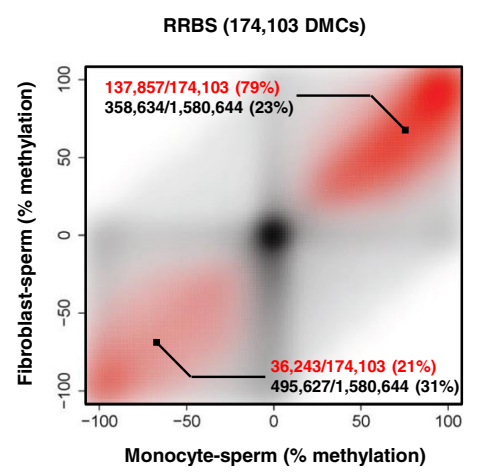

Fig. 3 Two distinct sets of differentially methylated regions and differentially methylated CpGs display undermethylation in sperm. a Venn diagram showing the DMRs identified using MeDIP-chip in sperm, fibroblasts and liver. A total of 1678 DMRs specific to the comparison between sperm and somatic cells was obtained (in red). $\mathbf{b}$ Venn diagram showing the DMCs identified using RRBS in sperm, fibroblasts and monocytes. A total of 174,103 DMCs specific to the comparison between sperm and somatic cells was obtained (in red). $\mathbf{c}$ The CpG positions included in the 3780 DMRs identified between sperm and fibroblasts using MeDIP were extracted. The Venn diagram shows the intersection between these CpGs and the 450,971 DMCs identified between sperm and fibroblasts using RRBS. $\mathbf{d}$, e Scatterplots showing the methylation differences between two somatic tissues and sperm, for all regions or CpGs used during differential analysis (in black; background) and for DMRs/DMCs specific to the comparison between sperm and somatic cells (in red). The proportions of background regions/CpGs overmethylated (upper right edge) and undermethylated (lower left edge) in both somatic tissues compared to sperm are indicated in black. The proportions of DMRs/DMCs overmethylated and undermethylated in both somatic tissues compared to sperm are indicated in red. $\mathbf{d}$ Differences in methylation between liver and sperm ( $\operatorname{Pr}_{\text {liver }}-\operatorname{Pr}_{\text {sperm; }} x$-axis) and between fibroblasts and sperm ( $\operatorname{Pr}_{\text {fibroblasts }}$ $\operatorname{Pr}_{\text {spermi }} y$-axis) for regions and DMRs identified using MeDIP (see Additional file 1: Supplementary methods for the definition of $\operatorname{Pr}_{\text {sperm, }} \operatorname{Pr}_{\text {liver }}$ and $\operatorname{Pr}_{\text {fibroblasts }}$ ). e Differences in methylation between monocytes and sperm ( $x$-axis) and between fibroblasts and sperm ( $y$-axis) for CpGs and DMCs identified using RRBS

ran from the lower left-hand corner to the upper righthand corner, meaning that these DMRs/DMCs behaved similarly in the two somatic cell types when compared to sperm. Most strikingly, a great majority of sperm-specific DMRs/DMCs (68\% for MeDIP and 79\% for RRBS) were grouped in the upper right-hand corner, indicating that they were hypomethylated in sperm when compared to the two somatic cell types examined.

Taken together, these results demonstrated that using two complementary technologies we were able to identify two distinct subsets of DMRs/DMCs specific to the comparison between sperm and somatic cells, most of them being less methylated in sperm. These hypomethylated sperm-specific DMRs/DMCs (hypo-DMRs/DMCs) could therefore partly explain the lower global DNA methylation of sperm observed in LUMA which was particularly marked in cattle.

\section{Hypomethylation in bull sperm targets specific genomic features and functions}

To determine whether specific gene ontology (GO) terms were enriched in the sperm hypomethylated regions, we 
next annotated the hypo-DMRs identified by MeDIP relative to genes. Consistent with the microarray design, most of the 1144 hypo-DMRs were located in or close to genes according to the criteria described in the Methods, resulting in a list of 701 unique genes which were then subjected to DAVID analysis. Significant enrichments were found for biological processes such as sexual reproduction (36 genes), fertilization (15 genes) and RNA transport (11 genes). Further analysis using a more restrictive list of GO terms led to the identification of functional clusters involved in mRNA processing (Fig. 4a) and meiosis/spermatogenesis (Fig. 4b).

Because CpGs targeted by RRBS are scattered along the genome, we then started to characterize the hypoDMCs identified by RRBS relative to different genomic features (genes, CpG density and overlapping repeats; Fig. 5a). The most remarkable observation was a dramatic enrichment of hypo-DMCs for repeats (24.5\% vs. $13.2 \%$ in background; right panel), and particularly for satellites $(64.7 \%$ vs. $17.8 \%)$. In order to get a more precise picture of the methylation status of repetitive elements by rescuing some of the information included in the ambiguous reads, we aligned the reads on a Repbase artificial genome containing the consensus sequence of each bovine repeat (see Additional file 1: Supplementary methods for details, and Additional file 4 and Additional file 1: Table S8 for data). The hypomethylation of sperm was clear in satellites and also in rDNA repeats encoding ribosomal RNAs (Additional file 1: Figure S3). We therefore concluded from both CpGs targeted by uniquely mapped reads (that had been used to identify hypoDMC) and CpGs targeted by ambiguous reads, that specific families of repetitive elements were massively hypomethylated in bovine sperm.

Regarding gene features with respect to RRBS data, the proportion of genes containing hypo-DMCs was relatively unchanged compared with background (Fig. 5a, left panel) , but interestingly, exons were more frequently represented (26.8\% vs. $13.8 \%$ in background) while promoterTSS were represented less than in background (4.8\% vs. 13.1\%). The distribution of hypo-DMCs in CGIs, shores and shelves was identical to that observed with the background (middle panel). We investigated whether specific GO terms were enriched in gene features displaying a different representation in hypo-DMCs and background. For exonic hypo-DMCs, which accounted for 2713 unique genes, significant enrichments were found for biological processes such as cell adhesion (213 genes), the regulation of signaling (382 genes) and cell migration (177 genes), and one main functional cluster related to cell adhesion could also be identified (Fig. 5b). For hypo-DMCs located in promoter-TSS, which accounted for 1200 unique genes, the most enriched biological process was sexual reproduction (44 genes), and two functional clusters were identified (Fig. 5c) as being related to piRNA metabolism (left panel) and to meiosis and spermatogenesis (right panel).

From an analysis of both hypo-DMRs obtained in MeDIP and hypo-DMCs identified through RRBS, we therefore concluded that undermethylation in sperm essentially targeted repeats and the promoters of genes

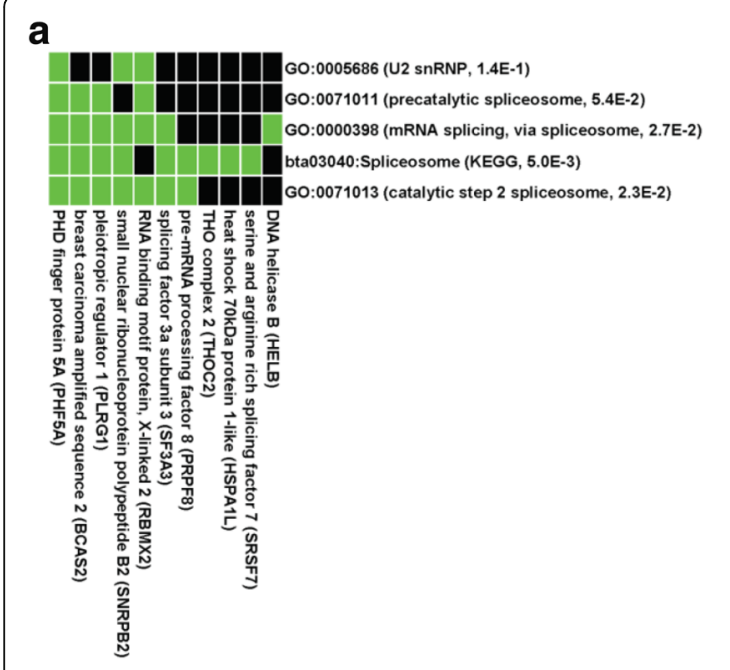

b

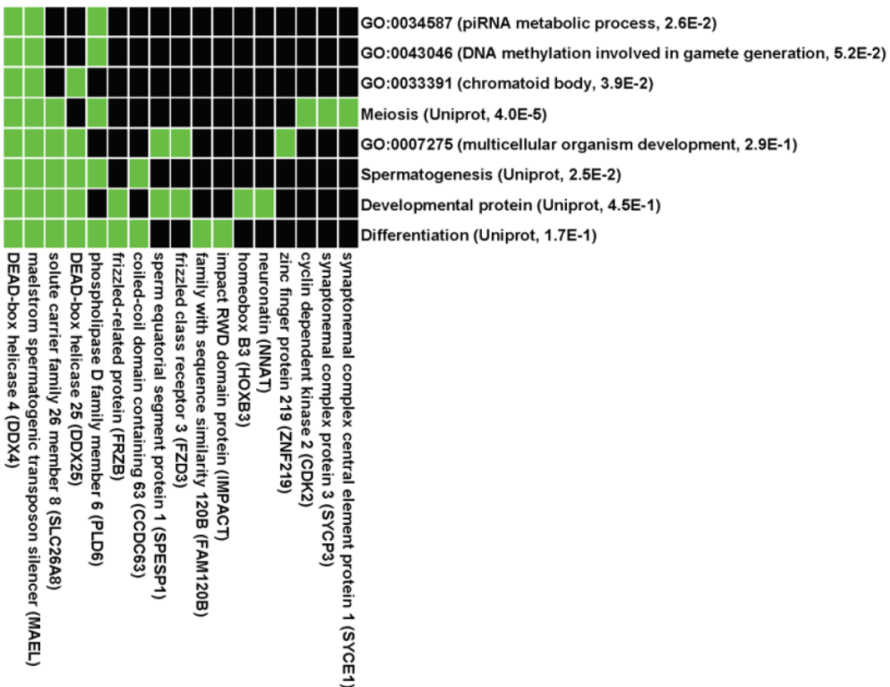

Fig. 4 Hypo-DMRs identified by MeDIP-chip target genes involved in mRNA processing and spermatogenesis. Genes containing the 1144 hypo-DMRs were subjected to DAVID analysis, with the regions of interest used as the background. Terms of gene ontology, pathways or Uniprot keywords enriched among the DMRs and their corresponding p-values are indicated, as are the genes present in each category. The green color on the heatmap represents a correspondence between a gene and a category. To limit the size of the heatmaps, only GO terms designated as DIRECT by DAVID were used for cluster generation. a Functional cluster related to mRNA processing. b Functional cluster related to meiosis and spermatogenesis 


\section{a}

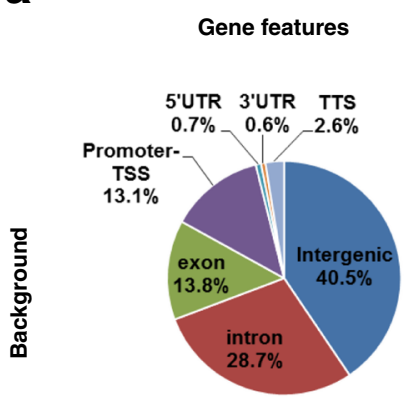

CpG density

Overlapping repeats
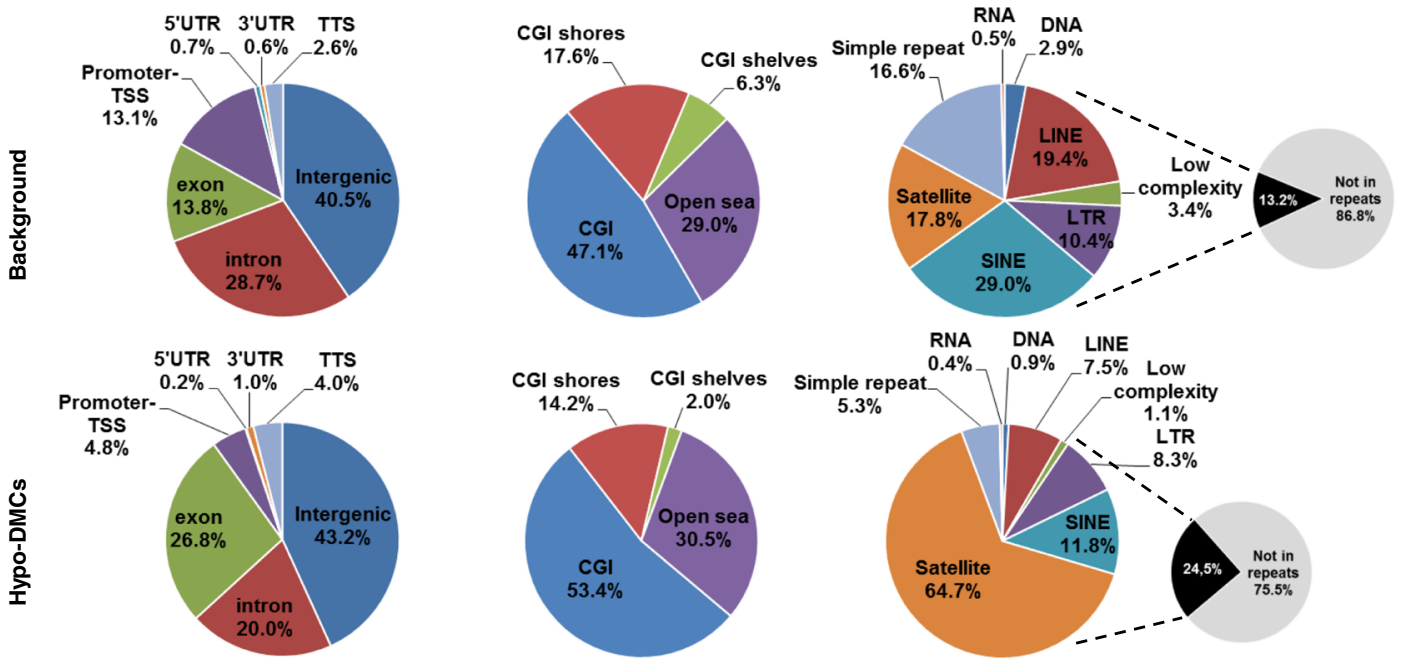

b

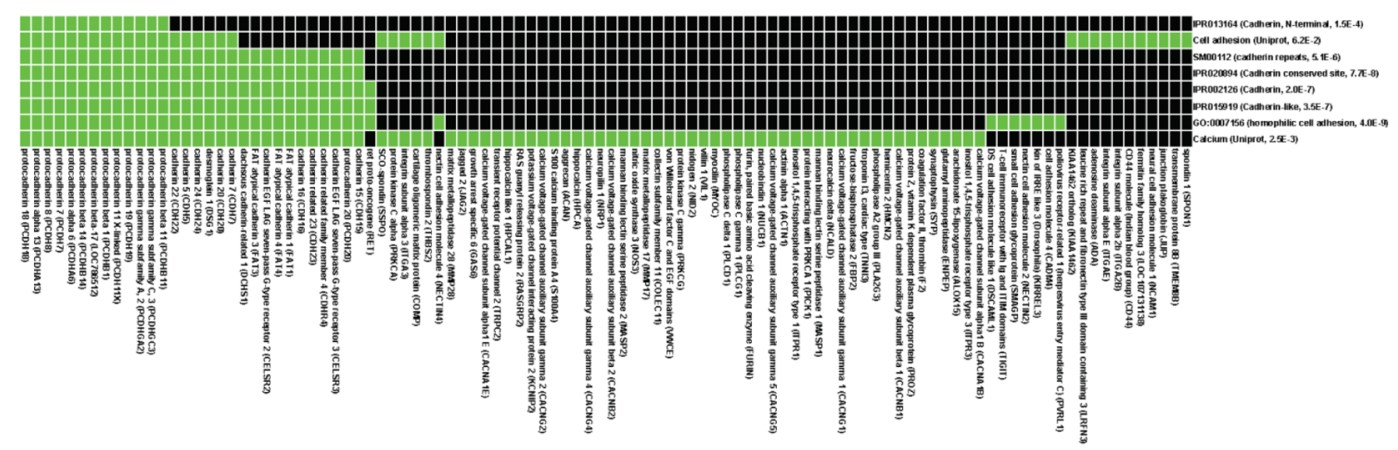

C
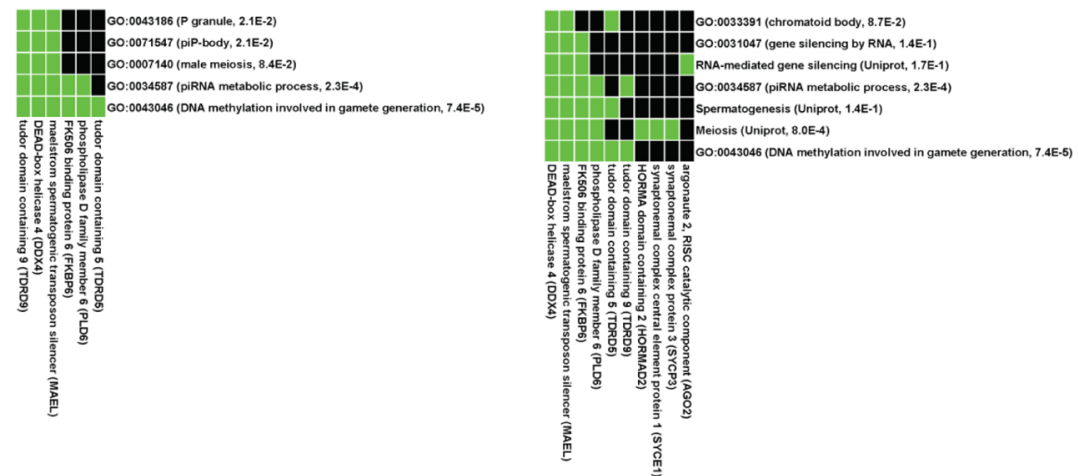

Fig. 5 Hypo-DMCs identified by RRBS target specific genomic features and functions. The 137,861 hypo-DMCs and 1,580,644 CpGs (background) were annotated relative to gene features, CpG density and overlapping repeats. a Distribution of hypo-DMCs and background CpGs among these genomic features. $\mathbf{b}$ Genes with hypo-DMCs located in exons were subjected to DAVID analysis, with genes from some of the 1,580,644 CpGs in exons used as the background. The heatmap represents a functional cluster related to cell adhesion. c Genes with hypo-DMCs located in promoter-TSS were subjected to DAVID analysis, with genes containing some of the 1,580,644 CpGs in promoter-TSS used as the background. The heatmaps represent functional clusters related to piRNA metabolism (left panel) and to meiosis and spermatogenesis (right panel). To limit the size of the heatmaps, only GO terms designated as DIRECT by DAVID were used for cluster generation 
important to spermatogenesis (which is the differentiation process that eventually leads to the mature sperm we analyzed), but also to genes involved in cell communication, signaling and migration that may be essential to both sperm functions and post-fertilization steps.

\section{Hypomethylation of four regions is confirmed by bisulfite-pyrosequencing}

Four regions were selected for validation, based on their hypomethylation in sperm, the presence of both DMRs obtained by MeDIP analysis and DMCs obtained by RRBS analysis whenever possible, and their position relative to genes involved in sperm functions. Figure 6a shows the detailed localization of these regions together with their coverage and individual methylation in both MeDIP and RRBS. LSM4, which contained a hypo-DMR, is a gene involved in RNA processing [45]. Genes SYCP3 and DDX4, which contained both hypo-DMRs and hypo-DMCs identified in our study, play a major role in spermatogenesis insofar as either mutation or aberrant

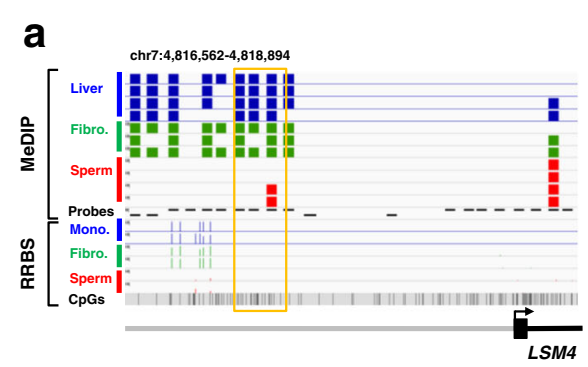

b
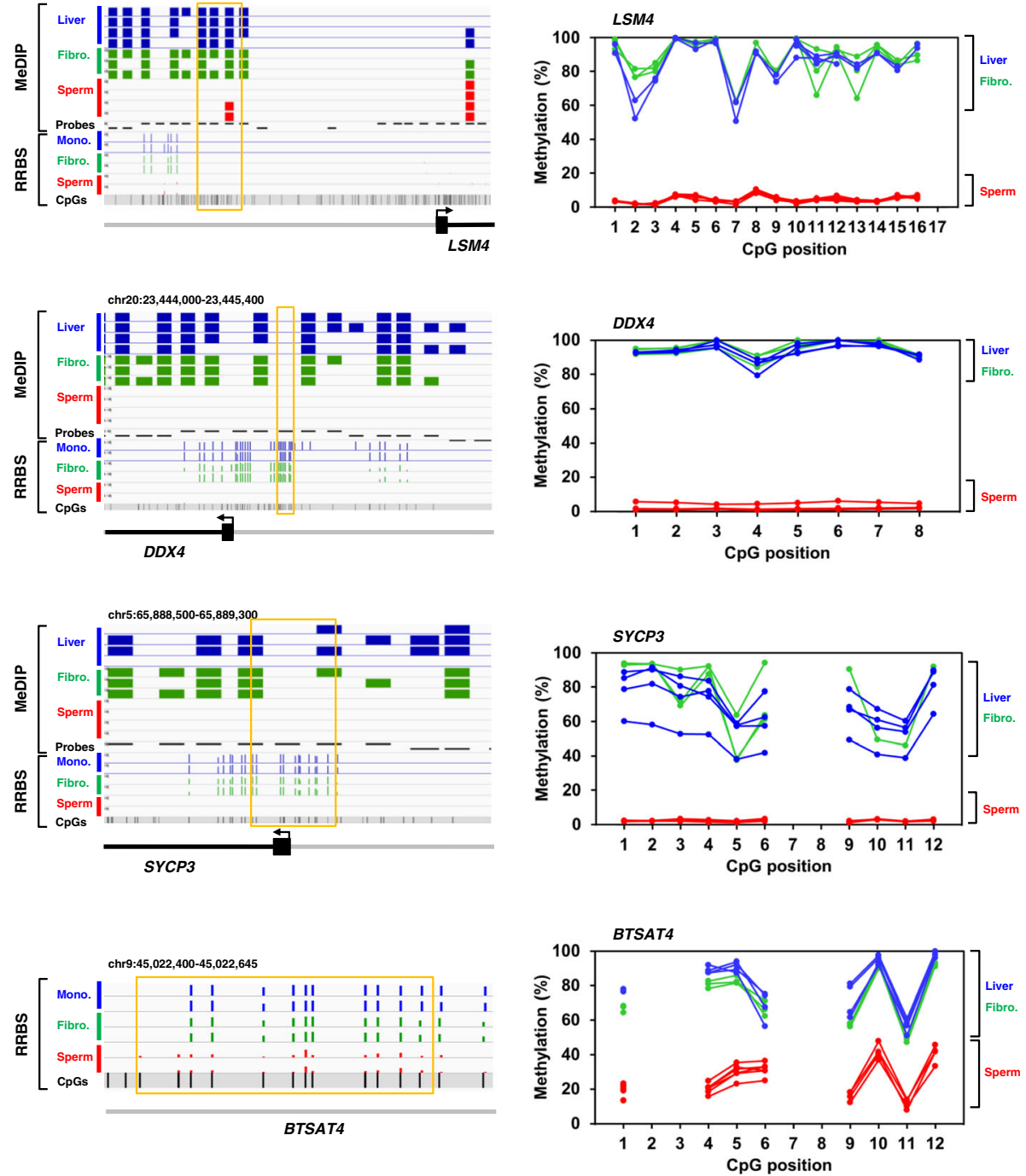

Fig. 6 Validation by bisulfite-pyrosequencing. a IGV browser views of the gene regions targeted for pyrosequencing. In the MeDIP-chip panels, the "Probes" track indicates the probe positions on the microarray. The blue, green, and red bar charts represent probes with signal enrichment in the MeDIP fraction for liver, fibroblast and sperm samples, respectively. An absence of chart at a given probe position denotes that signal was not enriched in the MeDIP fraction. In the RRBS panels, the blue, green, and red bar charts represent the methylation percentages at each CpG 5500 position for monocyte, fibroblast and sperm samples, respectively. Individual CpGs are shown, as are the MeDIP probe classes based on CpG frequency (the upper, middle and lower bands represent high, intermediate and low class probes, respectively). The orange boxes delineate the regions analyzed by pyrosequencing. b Methylation percentages of the CpGs assayed by pyrosequencing in sperm $(n=6)$, fibroblasts $(n=3)$ and liver $(n=4)$. The difference between sperm and somatic cells is significant at every position $(p<0.05$, permutation test) 
methylation of these genes associate to male infertility [46, 47]. BTSAT4 was the most frequently represented bovine satellite in our RRBS data and displayed undermethylation in sperm (Additional file 4). Overall, the four regions represented 42 analyzed CpGs. We used the pyrosequencing of bisulfite-converted DNA [40] to quantify the absolute methylation percentage of individual CpGs in sperm, liver and fibroblasts (Fig. 6b; genomic DNA from monocytes was in limited amounts and was saved for separate investigations). Consistent with the MeDIP data showing enriched probes along the LSM4 promoter in liver and fibroblasts but not in sperm, the CpGs analyzed by pyrosequencing were all hypomethylated in sperm. In this region, the CpGs assessed by pyrosequencing were not covered by RRBS, but those in DDX4, SYCP3 and BTSAT4 were covered by the three techniques and displayed hypomethylation in sperm whatever the technique used. By pyrosequencing four additional CpGs, we also checked that one region specifically hypermethylated in sperm compared to somatic cells validated (Additional file 1: Figure S4).

In conclusion, the results obtained using MeDIP, RRBS and pyrosequencing were in excellent agreement, which validated the high-throughput data and led to the characterization of gene regions with methylation patterns specific to bull sperm.

\section{Discussion}

During this study, we performed DNA methylation analyses at different genome scales in order to exhaustively characterize the bovine sperm methylome. Our main findings were that global DNA methylation level was low in bull sperm compared with other species, and that bull sperm was less methylated than bovine somatic cells in the context of two genome-wide methylation assays targeting distinct genomic regions, namely RRBS and MeDIP-chip, with a focus on gene promoters.

The undermethylation of bull sperm compared to somatic cells agreed well with findings in other mammals and provides additional evidence of features of the male germline differentiation program being conserved across species. Hypomethylated loci have been identified for instance in the sperm of human and chimp using whole genome bisulfite sequencing [48] or the Infinium $450 \mathrm{~K}$ methylation platform $[19,49]$. Together with our work, these reports demonstrate that the undermethylated status of sperm is independent of both the genome coverage and resolution of the technology used to map DNA methylation, and suggest that the presence of hypomethylated loci is conserved among mammals. We found that promoters and exons of genes hypomethylated in bull sperm were enriched for biological processes essential to sperm functions, such as sexual reproduction, fertilization, cell adhesion and migration, meiosis, RNA transport and processing (including piRNA metabolism), and the regulation of signaling. Interestingly, genes involved in these processes displayed highly dynamic expression in post-natal mouse spermatogonial stem cells [50]. In human sperm, some of these processes (cell adhesion, sexual reproduction, meiosis and piRNA metabolism) are enriched in hypomethylated promoters [48]. Hypermethylation of the piRNA machinery in testes has also been associated with human spermatogenic disorders [51]. In several species including bovine, the undermethylation of mature spermatozoa could therefore reflect a dynamic sequence of past transcriptional events in the male germline differentiation program which are essential to sperm functions.

Another striking finding revealed by our RRBS data was the undermethylation of repetitive elements in bull sperm, especially satellites. How to analyze repetitive sequences is still a matter of debate because of potential mapping artefacts [52, 53]. We initially decided to discard ambiguous reads, which may have led to an underestimation of the total contribution of repeats to hypomethylated loci in sperm. Alternatively, we aligned the sequences on an artificial genome that contained one copy of each bovine repetitive element, and were able to confirm the undermethylation of satellites and rDNA repeats encoding ribosomal RNAs in bull sperm. The undermethylation of satellites in sperm has long been described in several species, including bovine, by analyses of candidate sequences [54-56]. More recently, the undermethylated status of satellites in human and chimp sperm has been generalized to the whole genome [48]. Satellites are essential components of the constitutive heterochromatin in mammals, and this function is partly mediated by DNA methylation [57]. Satellites play key roles in chromosome structure, stability and segregation. Through their high molecular dynamics and ability to drive chromosome rearrangements, they are considered to be major actors in diseases such as cancer, but also in genome evolution and speciation [58]. The significance of satellite undermethylation in sperm could be related to the transcriptional burst that arises from paternal satellites in early mouse development, which is necessary for normal formation of the heterochromatin in embryos and for developmental progression [59]. Consistent with this important transcriptional activity, satellites remain hypomethylated after fertilization in normal preimplantation embryos $[56,60]$. In contrast, embryos resulting from somatic cell nuclear transfer (SCNT) and have a reduced development potential, display somatic-like hypermethylated satellites in the mouse [56] and bovine [61-63]. Of note, the hypermethylation of satellites seems to persist in the sperm of adult SCNT-derived 
bulls [64], suggesting that it has resisted the two waves of epigenetic reprogramming that occur during early development and germ cell differentiation.

Strikingly, the sperm-specific hypomethylated sequences identified throughout this study, and which were particularly enriched in genes related to germline differentiation and in satellite and rDNA repeats, displayed several common features. Firstly, these hypomethylated sequences have previously been described as targets of DNMT3B de novo DNA methyltransferase. Indeed, the methylation of satellites is half-reduced in the germline of newborn male mice deficient for DNMT3B [65]. In humans, DNMT3B mutations lead to the ICF syndrome (Immunodeficiency Centromeric instability Facial anomalies). In somatic cells, this disease is associated with a hypomethylated status of germline genes and centromeric satellites that closely mimics that of gametes, affecting nuclear organization and chromosome stability [66]. Another common feature shared by sperm-specific hypomethylated sequences is that they partly remain associated to nucleosomes in mature spermatozoa, as reported for genes involved in RNA processing and for repetitive elements (including centromeric satellites) in humans and bovine [67], and for satellites and rDNA repeats in bovine [68]. In addition, sperm histone retention particularly affects $\mathrm{CpGs}$ that lack methylation in humans [49] and the mouse [69]. The association with retained nucleosomes in sperm, together with the important function of paternal satellite transcripts in early embryos and the hypermethylation of satellites in SCNT embryos, support the hypothesis that regions which are hypomethylated in sperm play a fundamental role not only in germline differentiation but also in post-fertilization epigenetic reprogramming.

The final question arising from our study originates from the intriguing finding that global methylation at CCGG sites was more than $10 \%$ lower in bull sperm than in any other species investigated (sheep, horse, pig, mouse, goat and human), which remains to be confirmed using larger samples. Because satellites are undermethylated in the sperm of many species, the global undermethylation of bull sperm could partly be explained by the larger amount of satellite sequences present in the bovine genome (eight satellite components representing $23 \%$ of the total genomic content; [70]). We annotated the CCGG sites relative to the genomic features available in different species, and indeed observed that CCGGs overlapping satellites represented $1.6 \%$ of all CCGGs in bovine vs. 0.1 to $0.6 \%$ in other species. From a purely mathematical point of view, the low percentage of CCGG sites present in satellites whatever the species probably did not accounted for the $>10 \%$ difference in sperm methylation. However, it should be kept in mind that the repetitive nature of satellites precludes their correct integration in genome assemblies, which probably led to an underestimation of their contribution to global CCGG methylation. Although we cannot rule out that the weaker global methylation in bull sperm is due to a higher representation of bovine satellites in CCGGs, an alternative explanation might be that satellite methylation is quantitatively lower in bull sperm than in the sperm of other species. This is supported by an old report which demonstrated that relative to somatic tissues, most satellites are largely undermethylated in the sperm of cattle while they are only slightly undermethylated in mouse sperm [54]. The abundance of satellites in the bovine genome, together with their low methylation content in male germ cells, may contribute to explaining some of the bovine-specific features of meiotic recombination. Crossing-over events are more frequently observed in the spermatocytes of Bos taurus than in those of related Bovidae species (wildebeests; [71]). Moreover, the meiotic recombination rate in cattle is particularly elevated in males, while in most species it is higher in females [72, 73]. The frequency of crossing-overs is usually low in repeat-rich domains associated with heterochromatin [74]; however, the weak methylation of satellites in bull germ cells probably reflects a particular chromatin structure that may promote crossing-overs. The undermethylation of bull spermatozoa may also have contributed to shaping the bovine genome. Indeed, segmental duplications in the bovine reference genome are particularly enriched for satellite repeats that are undermethylated in bull sperm, including BTSAT4 [75]. Segmental duplications promote both chromosome rearrangements that drive bovine genome evolution (as indicated by their enrichment in the vicinity of cattle-specific evolutionary breakpoints [29]), and inter-individual variability through their ability to promote CNVs [76]. The role of segmental duplications in structural variations of the bovine genome might be mediated by hypomethylated sequences in the bull germline. In support of this hypothesis, human-specific evolutionary rearrangements and CNVs associate not only with low copy repeats and the deletions/duplications they generate, but also with hypomethylated regions of human sperm [77], thus providing a potential link between hypomethylation in the germline and genome structural variation.

\section{Conclusions}

By means of a thorough characterization of bull sperm DNA methylation at different genome scales, this study has provided evidence that bull spermatozoa are less methylated when compared to not only bovine somatic cells but also the sperm of other mammals. The sequences undermethylated in bull 
sperm are conserved across species, which may denote an important role in germline differentiation and in post-fertilization epigenetic reprogramming. The cattle-specific lower methylation at CCGG sites may be partly related to the abundance of satellites in the bovine genome and to their undermethylated status in the male germline. Given the potential evolutionary implications of these findings, it would be of considerable interest to quantify DNA methylation at different stages of bovine male germline differentiation in order to understand when and how this undermethylation takes place.

\section{Additional files}

\section{Additional file 1: is a pdf file containing supplementary methods,} supplementary references, eight supplementary tables and four supplementary figures. Table S1. reference genomes used for in silico analyses and origin of the files used for annotation. Table S2. in silico characterization of bovine reduced restriction (RR) genomes generated using different size selection criteria. Table S3. comparison of RR genomes obtained with a 40-290 bp selection size window in different species. Table S4. primers and PCR conditions used to generate the pyrosequencing templates. Table S5. pyrosequencing primers. Table S6. library characterization, mapping efficiency on the bovine genome (UMD3.1), coverage and average methylation in RRBS libraries. Table S7. results of comparisons between tissues by RRBS. Table S8. mapping efficiency on a Repbase artificial bovine genome, coverage and average methylation in RRBS libraries. Figure S1. Bootstrap analysis of global CCGG methylation in bull sperm from four different breeds. Figure S2. Genotyping of bull sperm and blood samples. Figure S3. Average methylation percentages for CpGs 5-500 and CpGs > 500 in each cell type, in reads uniquely aligned on a Repbase bovine artificial genome. Figure S4. Pyrosequencing of CpGs hypermethylated in sperm. (PDF $1840 \mathrm{~kb}$ )

Additional file 2: is a Microsoft Excel file listing the DMCs identified using RRBS. This file includes three datasheets corresponding to the pairwise comparisons between sperm, fibroblasts and monocytes. (XLSX 84756 kb)

Additional file 3: is a Microsoft Excel file listing the DMRs identified using MeDIP. This file includes three datasheets corresponding to the pairwise comparisons between sperm, fibroblasts and liver. One DMR may be present in several lanes if shared by several promoters. (XLSX $821 \mathrm{~kb})$

Additional file 4: is a Microsoft Excel file listing the consensus sequences of each bovine repetitive element as defined in Repbase and the average methylation percentages for CpGs 5-500 and CpGs $>500$ in each RRBS sample. (XLSX $16 \mathrm{~kb}$ )

\section{Abbreviations}

CGI: CpG island; CNV: Copy number variation; DAVID: Database for Annotation, Visualization and Integrated Discovery; DMC: Differentially methylated CpG; DMR: Differentially methylated region; DTT: Dithiothreitol; GO: Gene ontology; IGV: Integrative Genomics Viewer; LUMA: Luminometric methylation assay; MeDIP: Methylated DNA immunoprecipitation; PBMCs: Peripheral blood mononuclear cells; PBS: Phosphate buffer saline; PCA: Principal component analysis; RR genome: Reduced representation genome; RRBS: Reduced representation bisulfite sequencing; SCNT: Somatic cell nuclear transfer; TSS: Transcription start site; TTS: Transcription termination site

\section{Acknowledgements}

We would like to thank Evolution, Umotest, Awe, GEN'IATEST, OSON, Capgenes, LNCR, Michèle Magistrini and Rachel Lévy for providing semen samples; Véronique Duranthon and Delphine Dubé for providing fibroblasts and Chaneze Mehalla for help with the pyrosequencing of DDX4 and SYCP3.
We are grateful to the Genotoul bioinformatics platform Toulouse MidiPyrenees (Bioinfo Genotoul) for providing computing and storage resources.

\section{Funding}

This work was supported by grants from the French National Research Agency (grant ANR-13-LAB3-0008-01 'SeQuaMol' and grant ANR-11-INBS -0003 in the framework of the 'Investing for the Future' program). SeQuaMol funding allowed the collection of large number of animal semen samples and molecular analyses (MeDIP-chip, RRBS, bisulfite conversion, pyrosequencing) The grant ANR-11-INBS -0003 supported molecular analyses such as LUMA. The funders had no role in the design of the study and collection, analysis, and interpretation of data and in writing the manuscript. JPP (phD student) was supported by the French Ministry of Higher Education and Research and was a fellow of the ABIES doctoral school. HAA was supported by the PremUp foundation.

\section{Availability of data and materials}

Additional data files are provided (see above). The MeDIP-chip and RRBS datasets supporting the results of this article are available in the NCBI Gene Expression Omnibus database under accession numbers GSE102960 (MeDIP) and GSE102169 (RRBS).

\section{Authors' contributions}

JPP carried out the experiments, data analysis and drafting of the manuscript. ES participated in conception of the study, collected the samples and performed the experiments. AP performed the LUMA experiments and interpreted the data. $\sqcup$ performed the bioinformatics and statistical analyses of MeDIP data. $\amalg, F P$, HAA and MG developed the bioinformatics pipeline for RRBS data analysis and contributed to critical revision of the manuscript. MW supervised the RRBS library preparations and contributed to critical revision of the manuscript. CLD, SF and DB contributed to sample collection and to critical revision of the manuscript. LS and $\mathrm{HJ}$ obtained funding and participated in the conception of the study and editing of the manuscript. HK coordinated the study and carried out the experiments, data analysis and drafting of the manuscript. All authors have read and approved the final manuscript.

\section{Ethics approval and consent to participate}

All study methods were implemented in accordance with EU guidelines and regulations (Directive 2010/63/UE). For animals maintained in INRA facilities, the experimental protocols were approved by the INRA local Ethics Committee (COMETHEA, authorization numbers 12/160 and Méjusseaumes Animal Care committee 0162503). Mice semen samples were collected from 7-week-old male C57BI/6JOlaHsd mice supplied by Harlan Laboratory (Venray, Netherlands) and euthanized by cervical dislocation. The bull samples were provided by commercial companies: Montbéliarde breed by GEN'IATEST (Roulans, France) and UMOTEST (Ceyzeriat, France), Holstein and Normande breeds by EVOLUTION (Rennes, France) and Belgian White Blue Breed by AWE (Ciney, Belgium); the ram, goat and boar semen were also supplied by commercial companies, Oson (France), CAPGENES (France) and Laboratoire National de Contrôle des Reproducteurs (LNCR, France), respectively. Stallion semen was supplied by Dr. M. Magistrini (UMR INRA 0085 PRC, Nouzilly, France). Human sperm samples from patients included in a PHRC METASPERME study, coordinated by Dr. R. Levy (Laboratoire d'Histologie Embryologie Cytogénétique CECOS, Hôpital Jean Verdier, Bondy, France); this study received the approval from French ethics board (Conseil d'évaluation éthique pour les recherches en santé, CERES) and all the patients gave their informed written consent to participate.

\section{Competing interests}

The authors declare that they have no competing interests.

\section{Publisher's Note}

Springer Nature remains neutral with regard to jurisdictional claims in published maps and institutional affiliations.

\section{Author details}

'UMR BDR, INRA, ENVA, Université Paris Saclay, 78350 Jouy en Josas, France. ${ }^{2}$ Present Address: Laboratory of Animal Reproduction, Department of Biological Sciences, Faculty of Science and Engineering, University of Limerick, Limerick, Ireland. ${ }^{3}$ ALLICE, 149 rue de Bercy, 75012 Paris, France. 
${ }^{4}$ Present Address: Institut Curie, PSL Research University, CNRS, UMR3664, 75005 Paris, France. ${ }^{5}$ Present Address: Sorbonne Universités, UPMC Univ Paris 06, CNRS, UMR3664, 75005 Paris, France. ${ }^{6}$ CNRS, Université de Strasbourg, UMR7242 Biotechnologie et signalisation cellulaire, 300 bd Sébastien Brant, 67412 IIIkirch cedex, France. ${ }^{7}$ UMR GABI, INRA, AgroParisTech, Université Paris Saclay, 78350 Jouy en Josas, France. ${ }^{8}$ UMR CNRS/USTL 8576, UGSF, Villeneuve D'Ascq, France.

\section{Received: 12 September 2017 Accepted: 7 May 2018} Published online: 29 May 2018

\section{References}

1. Carrell DT. Epigenetics of the male gamete. Fertil Steril. 2012;97(2):267-74

2. Tang WW, Kobayashi T, Irie N, Dietmann S, Surani MA. Specification and epigenetic programming of the human germ line. Nat Rev Genet. 2016; 17(10):585-600.

3. Yao C, Liu Y, Sun M, Niu M, Yuan Q, Hai Y, Guo Y, Chen Z, Hou J, Liu Y, et al. MicroRNAs and DNA methylation as epigenetic regulators of mitosis, meiosis and spermiogenesis. Reprod. 2015;150(1):R25-34.

4. Bao J, Bedford MT. Epigenetic regulation of the histone-to-protamine transition during spermiogenesis. Reprod. 2016;151(5):R55-70.

5. Gannon JR, Emery BR, Jenkins TG, Carrell DT. The sperm epigenome: implications for the embryo. Adv Exp Med Biol. 2014;791:53-66.

6. Boissonnas CC, Jouannet $\mathrm{P}$, Jammes H. Epigenetic disorders and male subfertility. Fertil Steril. 2013;99(3):624-31.

7. Boissonnas CC, Abdalaoui HE, Haelewyn V, Fauque P, Dupont JM, Gut I, Vaiman D, Jouannet $\mathrm{P}$, Tost J, Jammes $\mathrm{H}$. Specific epigenetic alterations of IGF2-H19 locus in spermatozoa from infertile men. Eur J Human Genet : EJHG. 2010;18(1):73-80.

8. Nanassy L, Carrell DT. Abnormal methylation of the promoter of CREM is broadly associated with male factor infertility and poor sperm quality but is improved in sperm selected by density gradient centrifugation. Fertil Steril. 2011;95(7):2310-4

9. Lambrot R, Xu C, Saint-Phar S, Chountalos G, Cohen T, Paquet M, Suderman M, Hallett M, Kimmins S. Low paternal dietary folate alters the mouse sperm epigenome and is associated with negative pregnancy outcomes. Nat Commun. 2013:4:2889.

10. Martinez D, Pentinat T, Ribo S, Daviaud C, Bloks WW, Cebria J, Villalmanzo N, Kalko SG, Ramon-Krauel M, Diaz R, et al. In utero undernutrition in male mice programs liver lipid metabolism in the second-generation offspring involving altered Lxra DNA methylation. Cell Metab. 2014;19(6):941-51.

11. Radford EJ, Ito M, Shi H, Corish JA, Yamazawa K, Isganaitis E, Seisenberger S, Hore TA, Reik W, Erkek S, et al. In utero effects. In utero undernourishment perturbs the adult sperm methylome and intergenerational metabolism. Sci. 2014;345(6198):1255903.

12. Aston Kl, Uren PJ, Jenkins TG, Horsager A, Cairns BR, Smith AD, Carrell DT. Aberrant sperm DNA methylation predicts male fertility status and embryo quality. Fertil Steril. 2015; https://doi.org/10.1016/j.fertnstert.2015.08.019.

13. Salas-Huetos A, Blanco J, Vidal F, Godo A, Grossmann M, Pons MC, Fernandez SF, Garrido N, Anton E. Spermatozoa from patients with seminal alterations exhibit a differential micro-ribonucleic acid profile. Fertil Steril. 2015;104(3):591-601.

14. Ni K, Spiess AN, Schuppe HC, Steger K. The impact of sperm protamine deficiency and sperm DNA damage on human male fertility: a systematic review and meta-analysis. Androl. 2016;4(5): 789-99.

15. de Castro Barbosa T, Ingerslev LR, Alm PS, Versteyhe S, Massart J, Rasmussen M, Donkin I, Sjogren R, Mudry JM, Vetterli L, et al. Highfat diet reprograms the epigenome of rat spermatozoa and transgenerationally affects metabolism of the offspring. Mol Metab. 2016;5(3):184-97.

16. Sharma U, Conine CC, Shea JM, Boskovic A, Derr AG, Bing XY, Belleannee C, Kucukural A, Serra RW, Sun F, et al. Biogenesis and function of tRNA fragments during sperm maturation and fertilization in mammals. Sci. 2016; 351(6271):391-6.

17. Kobayashi N, Miyauchi N, Tatsuta N, Kitamura A, Okae H, Hiura H, Sato A, Utsunomiya T, Yaegashi N, Nakai K, et al. Factors associated with aberrant imprint methylation and oligozoospermia. Sci Rep. 2017;7:42336

18. Jenkins TG, Aston Kl, Meyer TD, Hotaling JM, Shamsi MB, Johnstone EB, Cox KJ, Stanford JB, Porucznik CA, Carrell DT. Decreased fecundity and sperm
DNA methylation patterns. Fertil Steril. 2016; https://doi.org/10.1016/j. fertnstert.2015.09.013.

19. Urdinguio RG, Bayon GF, Dmitrijeva M, Torano EG, Bravo C, Fraga MF, Bassas L, Larriba S, Fernandez AF, Aberrant DNA. Methylation patterns of spermatozoa in men with unexplained infertility. Hum Reprod. 2015;30(5): 1014-28.

20. Bourc'his D, Bestor TH. Meiotic catastrophe and retrotransposon reactivation in male germ cells lacking Dnmt3L. Nat. 2004;431(7004):96-9.

21. Song N, Endo D, Song B, Shibata Y, Koji T. 5-aza-2'-deoxycytidine impairs mouse spermatogenesis at multiple stages through different usage of DNA methyltransferases. Toxicol. 2016;361-362:62-72.

22. Barau J, Teissandier A, Zamudio N, Roy S, Nalesso V, Herault Y, Guillou F, Bourc'his D. The DNA methyltransferase DNMT3C protects male germ cells from transposon activity. Sci. 2016;354(6314):909-12.

23. Guo F, Yang B, Ju ZH, Wang XG, Qi C, Zhang Y, Wang CF, Liu HD, Feng MY, Chen $Y$, et al. Alternative splicing, promoter methylation, and functional SNPs of sperm flagella 2 gene in testis and mature spermatozoa of Holstein bulls. Reprod. 2014;147(2):241-52

24. Jena SC, Kumar S, Rajput S, Roy B, Verma A, Kumaresan A, Mohanty TK, De S, Kumar R, Datta TK. Differential methylation status of IGF2-H19 locus does not affect the fertility of crossbred bulls but some of the CTCF binding sites could be potentially important. Mol Reprod Dev. 2014;81(4):350-62.

25. Yao W, Li Y, Li B, Luo H, Xu H, Pan Z, Xie Z, Li Q. Epigenetic regulation of bovine spermatogenic cell-specific gene boule. PLoS One. 2015;10(6): e0128250.

26. Verma A, Rajput S, De S, Kumar R, Chakravarty AK, Datta TK. Genome-wide profiling of sperm DNA methylation in relation to buffalo (Bubalus bubalis) bull fertility. Theriogenology. 2014;82(5):750-9. e751

27. Kropp J, Carrillo JA, Namous H, Daniels A, Salih SM, Song J, Khatib H. Male fertility status is associated with DNA methylation signatures in sperm and transcriptomic profiles of bovine preimplantation embryos. BMC Genomics. 2017:18(1):280

28. Shojaei Saadi HA, O'Doherty AM, Gagne D, Fournier E, Grant JR, Sirard MA Robert C. An integrated platform for bovine DNA methylome analysis suitable for small samples. BMC Genomics. 2014;15:451.

29. Bovine Genome S, Analysis C, Elsik CG, Tellam RL, Worley KC, Gibbs RA, Muzny DM, Weinstock GM, Adelson DL, Eichler EE, et al. The genome sequence of taurine cattle: a window to ruminant biology and evolution. Science. 2009;324(5926):522-8.

30. Kader F, Ghai M. DNA methylation-based variation between human populations. Mol Genet Genomics : MGG. 2017;292(1):5-35

31. Ortiz I, Dorado J, Ramirez L, Morrell JM, Acha D, Urbano M, Galvez MJ, Carrasco JJ, Gomez-Arrones V, Calero-Carretero R, et al. Effect of single layer centrifugation using Androcoll-E-large on the sperm quality parameters of cooled-stored donkey semen doses. Animal. 2014;8(2):308-15.

32. Kiefer $\mathrm{H}$. Genome-wide analysis of methylation in bovine clones by methylated DNA immunoprecipitation (MeDIP). Methods Mol Biol. 2015;1222:267-80.

33. Karimi M, Johansson S, Stach D, Corcoran M, Grander D, Schalling M, Bakalkin G, Lyko F, Larsson C, Ekstrom TJ. LUMA (LUminometric methylation assay) -a high throughput method to the analysis of genomic DNA methylation. Exp Cell Res. 2006;312(11):1989-95.

34. Attig L, Vige A, Gabory A, Karimi M, Beauger A, Gross MS, Athias A, GallouKabani C, Gambert P, Ekstrom TJ, et al. Dietary alleviation of maternal obesity and diabetes: increased resistance to diet-induced obesity transcriptional and epigenetic signatures. PLoS One. 2013:8(6):e66816.

35. Kiefer H, Jouneau L, Campion E, Rousseau-Ralliard D, Larcher T, MartinMagniette ML, Balzergue S, Ledevin M, Prezelin A, Chavatte-Palmer P, et al. Altered DNA methylation associated with an abnormal liver phenotype in a cattle model with a high incidence of perinatal pathologies. Sci Rep. 2016:6:38869.

36. Huang d W, Sherman BT, Lempicki RA. Systematic and integrative analysis of large gene lists using DAVID bioinformatics resources. Nat Protoc. 2009; 4(1):44-57.

37. Gu H, Smith ZD, Bock C, Boyle P, Gnirke A, Meissner A. Preparation of reduced representation bisulfite sequencing libraries for genome-scale DNA methylation profiling. Nat Protoc. 2011;6(4):468-81.

38. Auclair G, Guibert S, Bender A, Weber M. Ontogeny of CpG island methylation and specificity of DNMT3 methyltransferases during embryonic development in the mouse. Genome Biol. 2014;15(12):545.

39. Bao W, Kojima KK, Kohany O. Repbase update, a database of repetitive elements in eukaryotic genomes. Mob DNA. 2015;6:11. 
40. Dupont JM, Tost J, Jammes H, Gut IG. De novo quantitative bisulfite sequencing using the pyrosequencing technology. Anal Biochem. 2004; 333(1):119-27

41. Li LC, Dahiya R. MethPrimer: designing primers for methylation PCRs. Bioinformatics. 2002;18(11):1427-31.

42. Weyrich A. Preparation of genomic DNA from mammalian sperm. Curr Protoc Mo Biol. 2012, Chapter 2:Unit 2;13:11-3.

43. Schubeler D. ESCl award lecture: regulation, function and biomarker potential of DNA methylation. Eur J Clin Investig. 2015;45(3):288-93.

44. Weber M, Davies JJ, Wittig D, Oakeley EJ, Haase M, Lam WL, Schubeler D. Chromosome-wide and promoter-specific analyses identify sites of differential DNA methylation in normal and transformed human cells. Nat Genet. 2005;37(8):853-62.

45. Arribas-Layton M, Dennis J, Bennett EJ, Damgaard CK, Lykke-Andersen J. The C-terminal RGG domain of human Lsm4 promotes processing body formation stimulated by arginine Dimethylation. Mol Cell Biol. 2016;36(17):2226-35.

46. Miyamoto T, Minase G, Okabe K, Ueda H, Sengoku K. Male infertility and its genetic causes. J Obstet Gynaecol Res. 2015;41(10):1501-5.

47. Cheng YS, Lu CW, Lin TY, Lin PY, Lin YM. Causes and clinical features of infertile men with nonobstructive azoospermia and histopathologic diagnosis of Hypospermatogenesis. Urol. 2017; https://doi.org/10.1016/j. urology.2017.03.026.

48. Molaro A, Hodges E, Fang F, Song Q, McCombie WR, Hannon GJ, Smith AD. Sperm methylation profiles reveal features of epigenetic inheritance and evolution in primates. Cell. 2011;146(6):1029-41.

49. Krausz C, Sandoval J, Sayols S, Chianese C, Giachini C, Heyn H, Esteller M. Novel insights into DNA methylation features in spermatozoa: stability and peculiarities. PLoS One. 2012;7(10):e44479.

50. Hammoud SS, Low DH, Yi C, Lee CL, Oatley JM, Payne CJ, Carrell DT, Guccione E, Cairns BR. Transcription and imprinting dynamics in developing postnatal male germline stem cells. Genes Dev. 2015;29(21):2312-24.

51. Heyn H, Ferreira HJ, Bassas L, Bonache S, Sayols S, Sandoval J, Esteller M Larriba S. Epigenetic disruption of the PIWI pathway in human spermatogenic disorders. PLoS One. 2012;7(10):e47892.

52. Royo H, Stadler MB, Peters AH. Alternative computational analysis shows no evidence for nucleosome enrichment at repetitive sequences in mammalian spermatozoa. Dev Cell. 2016;37(1):98-104.

53. Dansranjavin $T$, Schagdarsurengin $U$. The rationale of the inevitable, or why is the consideration of repetitive DNA elements indispensable in studies of sperm nucleosomes. Dev Cell. 2016;37(1):13-4.

54. Adams RL, Burdon RH, Fulton J. Methylation of satellite DNA. Biochem Biophys Res Commun. 1983;113(2):695-702.

55. Feinstein SI, Racaniello VR, Ehrlich M, Gehrke CW, Miller DA, Miller OJ. Pattern of undermethylation of the major satellite DNA of mouse sperm. Nucleic Acids Res. 1985;13(11):3969-78.

56. Yamagata K, Yamazaki T, Miki H, Ogonuki N, Inoue K, Ogura A, Baba T. Centromeric DNA hypomethylation as an epigenetic signature discriminates between germ and somatic cell lineages. Dev Biol. 2007;312(1):419-26.

57. Nishibuchi G, Dejardin J. The molecular basis of the organization of repetitive DNA-containing constitutive heterochromatin in mammals. Chromosom Res. 2017;25(1):77-87.

58. Biscotti MA, Olmo E, Heslop-Harrison JS. Repetitive DNA in eukaryotic genomes. Chromosom Res. 2015;23(3):415-20.

59. Probst AV, Okamoto I, Casanova M, El Marjou F, Le Baccon P, Almouzni G. A strand-specific burst in transcription of pericentric satellites is required for chromocenter formation and early mouse development. Dev Cell. 2010; 19(4):625-38.

60. Kaneda M, Akagi S, Watanabe S, Nagai T. Comparison of DNA methylation levels of repetitive loci during bovine development. BMC Proc. 2011;5(Suppl 4):S3.

61. Kang YK, Lee HJ, Shim JJ, Yeo S, Kim SH, Koo DB, Lee KK, Beyhan Z, First NL, Han YM. Varied patterns of DNA methylation change between different satellite regions in bovine preimplantation development. Mol Reprod Dev. 2005:71(1):29-35.

62. Yamanaka K, Kaneda M, Inaba Y, Saito K, Kubota K, Sakatani M, Sugimura S, Imai K, Watanabe S, Takahashi M. DNA methylation analysis on satellite I region in blastocysts obtained from somatic cell cloned cattle. Anim Sci J. 2011:82(4):523-30

63. Yamanaka K, Sakatani M, Kubota K, Balboula AZ, Sawai K, Takahashi M. Effects of downregulating DNA methyltransferase 1 transcript by RNA interference on DNA methylation status of the satellite I region and in vitro development of bovine somatic cell nuclear transfer embryos. J Reprod Dev. 2011;57(3):393-402

64. Couldrey C, Wells DN. DNA methylation at a bovine alpha satellite I repeat CpG site during development following fertilization and somatic cell nuclear transfer. PLoS One. 2013;8(2):e55153.

65. Kato Y, Kaneda M, Hata K, Kumaki K, Hisano M, Kohara Y, Okano M, Li E, Nozaki M, Sasaki H. Role of the Dnmt3 family in de novo methylation of imprinted and repetitive sequences during male germ cell development in the mouse. Hum Mol Genet. 2007;16(19):2272-80.

66. Walton EL, Francastel C, Velasco G. Dnmt3b prefers germ line genes and Centromeric regions: lessons from the ICF syndrome and Cancer and implications for diseases. Biol. 2014;3(3):578-605.

67. Samans B, Yang Y, Krebs S, Sarode GV, Blum H, Reichenbach M, Wolf E, Steger K, Dansranjavin T, Schagdarsurengin U. Uniformity of nucleosome preservation pattern in mammalian sperm and its connection to repetitive DNA elements. Dev Cell. 2014;30(1):23-35.

68. Sillaste G, Kaplinski L, Meier R, Jaakma U, Eriste E, Salumets A. A novel hypothesis for histone-to-protamine transition in Bos taurus spermatozoa. Reprod. 2017;153(3):241-51.

69. Erkek S, Hisano M, Liang CY, Gill M, Murr R, Dieker J, Schubeler D, van der Vlag J, Stadler MB, Peters AH. Molecular determinants of nucleosome retention at $\mathrm{CpG}$-rich sequences in mouse spermatozoa. Nat Struct Mol Biol. 2013;20(7):868-75

70. Macaya G, Cortadas J, Bernardi G. An analysis of the bovine genome by density-gradient centrifugation. Preparation of the $\mathrm{dG}+\mathrm{dC}$-rich DNA components. Eur J Biochem. 1978:84(1):179-88.

71. Vozdova M, Sebestova H, Kubickova S, Cernohorska H, Vahala J, Rubes J. A comparative study of meiotic recombination in cattle (Bos taurus) and three wildebeest species (Connochaetes gnou, C. Taurinus taurinus and C. t. Albojubatus). Cytogenet Genome Res. 2013;140(1):36-45.

72. Ma L, O'Connell JR, VanRaden PM, Shen B, Padhi A, Sun C, Bickhart DM, Cole JB, Null DJ, Liu GE, et al. Cattle sex-specific recombination and genetic control from a large pedigree analysis. PLoS Genet. 2015:11(11):e1005387.

73. Kadri NK, Harland C, Faux P, Cambisano N, Karim L, Coppieters W, Fritz S, Mullaart $\mathrm{E}$, Baurain D, Boichard D, et al. Coding and noncoding variants in HFM1, MLH3, MSH4, MSH5, RNF212, and RNF212B affect recombination rate in cattle. Genome Res. 2016:26(10):1323-32.

74. Termolino P, Cremona G, Consiglio MF, Conicella C. Insights into epigenetic landscape of recombination-free regions. Chromosoma. 2016:125(2):301-8.

75. Liu GE, Ventura M, Cellamare A, Chen L, Cheng Z, Zhu B, Li C, Song J, Eichler EE. Analysis of recent segmental duplications in the bovine genome. BMC Genomics. 2009;10:571.

76. Fadista J, Thomsen B, Holm LE, Bendixen C. Copy number variation in the bovine genome. BMC Genomics. 2010;11:284.

77. Li J, Harris RA, Cheung SW, Coarfa C, Jeong M, Goodell MA, White LD, Patel A, Kang SH, Shaw C, et al. Genomic hypomethylation in the human germline associates with selective structural mutability in the human genome. PLoS Genet. 2012;8(5):e1002692.

\section{Ready to submit your research? Choose BMC and benefit from:}

- fast, convenient online submission

- thorough peer review by experienced researchers in your field

- rapid publication on acceptance

- support for research data, including large and complex data types

- gold Open Access which fosters wider collaboration and increased citations

- maximum visibility for your research: over $100 \mathrm{M}$ website views per year

At BMC, research is always in progress.

Learn more biomedcentral.com/submissions 